\title{
Transition to Agriculture in Central Europe: Body Size and Body Shape amongst the First Farmers
}

\author{
Janusz Piontek ${ }^{\mathrm{a}}$, Václav Vančata ${ }^{\mathrm{b}, \mathrm{c}}$ \\ ${ }^{a}$ Department of Human Evolutionary Anthropology, Institute of Anthropology, Adam Mickiewicz University, H. Wieniawskiego 1, 61-712 Poznań, Poland \\ ${ }^{b}$ Department of Biology, Faculty of Education, Charles University in Prague, M. D. Rettigové 411639 Praha, Czech Republic \\ 'Institute of Anthropology, Faculty of Science, Masaryk University, Vinařská 5, 60300 Brno, Czech Republic
}

\section{ARTICLE INFO}

\section{Article history:}

Received: 5 April 2012

Accepted: 31 August 2012

\section{Key words:}

Upper Palaeolithic

Mesolithic

Neolithic

Central Europe

body size

body shape

evolutionary trends

\begin{abstract}
$A B S T R A C T$
A number of anthropologists are convinced that changes in body build after the transition to agriculture had been a response to changes in environmental and social conditions. They argue that such changes were not connected with the genetic changes in Neolithic populations but were an adaptive response by the human organism to the new conditions of life in Neolithic agriculture society. The studied long bones characteristics in the Upper Palaeolithic, Mesolithic and Neolithic from Central Europe (length of long bones, body height, sexual dimorphism of long bones, proportion of long bones) contain three different morphological patterns of long bones - the Upper Palaeolithic, Mesolithic and Neolithic ones - had probably existed over the course of Homo sapiens microevolution in the Upper Palaeolithic/ Neolithic transitional period.

We have found significant differences between the Upper Palaeolithic and Neolithic populations in: (1) body size, body shape and limb proportions, (2) basic biomechanical limb parameters and limb robusticity, and (3) sexual dimorphism both in body size and shape, and in the proportions and biomechanical structure of limbs. The morphology of long bones of the Mesolithic populations of a transitional character, and "non-typical" agricultural the Corded Ware Cultures populations reveal certain traits similar to the Mesolithic populations. The morphology of Neolithic populations from two types of archaeological cultures (agricultural and pastorals) seems to be of a different character. The Corded Ware Cultures populations (pastorals) are in some respects similar to the Mesolithic populations, the Band Pottery Culture populations and Lengyel Culture (agricultural populations) show extremely different pattern morphology of long bones in relation to Upper Palaeolithic populations.

The differences observed between the Upper Palaeolithic and Neolithic populations resulted from multiple biological and cultural factors which combined to affect a new adaptive strategy and subsistence pattern.
\end{abstract}

\section{Introduction}

The Upper Palaeolithic-Mesolithic/Neolithic transition is extremely important for a deeper understanding of Homo sapiens evolution. Although there have been a number of attempts to investigate this problem using palaeontological data, e.g., by genetics and molecular genetics (e.g., Ammermann, Cavalli-Sforza 1984; Barbujani et al. 1994; Haak et. al. 2005), the most important information can be yielded by skeletal material only. Therefore, numerous

*Corresponding author. E-mail: piontek@amu.edu.pl authors have analysed relevant skeletal material to describe basic evolutionary trends over the Upper Palaeolithic/ Neolithic transition and the origin of agriculture (e.g., Formicolla 1983; 1993; 2003; Formicolla, Franceschi 1996; Formicolla, Giannecchini 1999; Frayer 1980; 1981; 1984; Frayer, Wolpoff 1985; Holliday 1997; Jacobs 1985a; 1992; 1993; Pinhasi 2004; Pinhasi, von Cramon-Traubadel 2009; 2012; Ruff 1987; Ruff et al. 1984; 1997; Vančata 1988; 1993; 2003; 2005).

There are two important methodological problems which impose major limitations on the possibility of broader interpretation and the generalization of the results from the above studies. 
1. The studies usually deal only with certain parts of the transition period. Some researchers have concentrated their efforts on the Upper Palaeolithic/Mesolithic transition (e.g., Formicolla, Giannecchini 1999; Frayer 1980; 1981; 1984; Frayer, Wolpoff 1985; Holliday 1997; Jacobs 1985a; 1985b), and as a result they were unable to analyse changes that occurred in the Neolithic. Others have limited their studies primarily to the Mesolithic and/or Neolithic period (e.g. Formicolla 1983; 1993; Formicolla, Franceschi 1996; Jacobs 1992; 1993), thus excluding the opportunity to understand the origin of the Mesolithic/Neolithic morphological patterns as well as the nature of the adaptive changes in this period. Some of studies, in turn, simplified the structure of the Upper Palaeolithic and Neolithic populations (e.g., Formicolla 1983; 1993; Formicolla, Franceschi 1996; Jacobs 1993;

Table 1. Upper Palaeolithic (Pre-glacial Maximum) group.

\begin{tabular}{|c|c|c|c|}
\hline Label & Group & Sex & Author \\
\hline$\overline{\text { Arene Candide 1-IP }}$ & $P G M$ & Male & Holliday 1995 \\
\hline B. Caviglione 1 & $P G M$ & Male & Holliday 1995 \\
\hline Barma Grande 2 & $P G M$ & Male & Formicolla 1988 \\
\hline Barma Grande 5 & $P G M$ & Male & Holliday 1995 \\
\hline Baousse de Torre 2 & $P G M$ & Male & Holliday 1995 \\
\hline Barma Grande 4 & $P G M$ & Male & Holliday 1995 \\
\hline Cro-Magnon 1 & $P G M$ & Male & Holliday 1995 \\
\hline Dolní Věstonice - XIII & $P G M$ & Male & Vančata $1994 ; 1997$ \\
\hline Dolní Věstonice - XIV & $P G M$ & Male & Vančata 1994 \\
\hline Dolní Věstonice - XVI & $P G M$ & Male & Vančata 1997 \\
\hline Grotte des Enfants 4 & $P G M$ & Male & Formicolla 1988 \\
\hline Grotte des Enfants 1 & $P G M$ & Male & Formicolla 1988 \\
\hline Kostenki 2 & $P G M$ & Male & Vančata, in preparation \\
\hline Mladec 21 & $P G M$ & Male & Holliday 1995 \\
\hline Mladec 22 & $P G M$ & Male & Holliday 1995 \\
\hline Neuessing 2 & $P G M$ & Male & Holliday 1995 \\
\hline Ohalo II H2 & $P G M$ & Male & Hershkovitz et al. 1995 \\
\hline Paviland & $P G M$ & Male & Holliday 1995 \\
\hline Pavlov & $P G M$ & Male & Vančata 1997 \\
\hline Předmostí - III & $P G M$ & Male & Matiegka 1938 \\
\hline Předmostí - IX & $P G M$ & Male & Matiegka 1938 \\
\hline Předmostí - XIV & $P G M$ & Male & Matiegka 1938 \\
\hline Sungir 1 & $P G M$ & Male & Vančata 1997 \\
\hline Sungir 2 & $P G M$ & Male-subadult & Vančata 1997 \\
\hline Aurignac & $P G M$ & Female & Vančata $1988 ; 1997$ \\
\hline Barma Grande 3 & $P G M$ & Female & Holliday 1995 \\
\hline Combe Capelle & $P G M$ & Female & Vančata $1988 ; 1997$ \\
\hline Dolní Věstonice - III & $P G M$ & Female & Vančata 1994; 1997 \\
\hline Dolní Věstonice - XV & $P G M$ & Female & Vančata 1994; 1997 \\
\hline Grotte des Enfants 5 & $P G M$ & Female & Holliday 1995 \\
\hline Grotte des Enfants 6 & $P G M$ & Female & Holliday 1995 \\
\hline La Rochette & $P G M$ & Female & Vančata 1997 \\
\hline Ostuni & $P G M$ & Female & Vacca, Novotny, pers. com. \\
\hline Paglicci 25 & $P G M$ & Female & Holliday 1995 \\
\hline Předmostí - I & $P G M$ & Female & Matiegka 1938 \\
\hline Předmostí - IV & $P G M$ & Female & Matiegka 1938 \\
\hline Předmostí - V & $P G M$ & Female & Matiegka 1938 \\
\hline Předmostí - X & $P G M$ & Female & Matiegka 1938 \\
\hline Sungir 3 & $P G M$ & Female-subadult & Vančata 1997 \\
\hline Cro-Magnon 2 & $P G M$ & & Holliday 1995 \\
\hline Cro-Magnon 3 & $P G M$ & & Holliday 1995 \\
\hline Pataud 4 & $P G M$ & & Holliday 1995 \\
\hline Pataud 5 & $P G M$ & & Holliday 1995 \\
\hline Pataud 6 & $P G M$ & & Holliday 1995 \\
\hline
\end{tabular}


Table 2. Upper Palaeolithic (Late Upper Palaeolithic) and Mesolithic groups.

\begin{tabular}{|c|c|c|c|}
\hline Label & Group & Sex & Author \\
\hline Arene Candide 10 & LUP & Male & Holliday 1995 \\
\hline Arene Candide 12 & LUP & Male & Holliday 1995 \\
\hline Arene Candide 2 & LUP & Male & Holliday 1995 \\
\hline Arene Candide 4 & LUP & Male & Holliday 1995 \\
\hline Arene Candide 5 & LUP & Male & Holliday 1995 \\
\hline Bichon 1 & LUP & Male & Holliday 1995 \\
\hline Chancelade 1 & LUP & Male & Holliday 1995 \\
\hline Gr. Continenza 1 & LUP & Male & Holliday 1995 \\
\hline Grotte des Enfants 3 & LUP & ?Female & Holliday 1995 \\
\hline Le Peyrat 5 & LUP & Male & Holliday 1995 \\
\hline Le Placard 16 & LUP & Male & Holliday 1995 \\
\hline Oberkassel 1 & LUP & Male & Vančata1988; 1997 \\
\hline Parabita 1 & LUP & Male & Holliday 1995 \\
\hline Romito 3 & LUP & Male & Holliday 1995 \\
\hline Veryier 1 & LUP & Male & Holliday 1995 \\
\hline Arene Candide 13 & LUP & Female & Holliday 1995 \\
\hline Arene Candide 14 & LUP & Female & Holliday 1995 \\
\hline Bruniquel 2 & LUP & Female & Holliday 1995 \\
\hline Cap Blanc 1 & LUP & Female & Holliday 1995 \\
\hline Farincourt 1 & LUP & Female & Holliday 1995 \\
\hline Kostenki 14 & LUP & Female & Vančata, in prep. \\
\hline Le Peyrat 6 & LUP & Female & Holliday 1995 \\
\hline Le Placard 15 & LUP & Female & Holliday 1995 \\
\hline Oberkassel 2 & LUP & Female & Holliday 1995 \\
\hline Parabita 2 & LUP & ?Male & Holliday 1995 \\
\hline Romito 4 & LUP & Female & Holliday 1995 \\
\hline Saint Germain-la-Riviere 1 & LUP & Female & Holliday 1995 \\
\hline San Teodoro 4 & LUP & Female & Holliday 1995 \\
\hline Arene Candide 1a & LUP & ?Male & Holliday 1995 \\
\hline La Madeleine 1 & LUP & & Holliday 1995 \\
\hline Laugerie Basse 54298a & LUP & ?Male & Holliday 1995 \\
\hline Laugerie Basse 54298b & LUP & ?Male & Holliday 1995 \\
\hline Laugerie Basse 54298c & LUP & ?Male & Holliday 1995 \\
\hline Laugerie Basse 9 & LUP & & Holliday 1995 \\
\hline San Teodoro 3 & LUP & & Holliday 1995 \\
\hline Bottendorf & Mesolithic & Male & Vančata 1997 \\
\hline Gough's Cave 1 & Mesolithic & Male & Holliday 1995 \\
\hline Gramat 1 & Mesolithic & Male & Holliday 1995 \\
\hline Hoëdic 5 & Mesolithic & ? Female & Holliday 1995 \\
\hline Hoëdic 6 & Mesolithic & ? Female & Holliday 1995 \\
\hline Hoëdic 9 & Mesolithic & ? Female & Holliday 1995 \\
\hline Los Azules 1 & Mesolithic & Male & Holliday 1995 \\
\hline Murzak Koba 2 & Mesolithic & Male & Vančata, in prep. \\
\hline Rastel & Mesolithic & Male & Holliday 1995 \\
\hline Rochereil & Mesolithic & Male & Holliday 1995 \\
\hline Téviec 11 & Mesolithic & Male & Holliday 1995 \\
\hline Téviec 16 & Mesolithic & Male & Holliday 1995 \\
\hline Hoëdic 8 & Mesolithic & Female & Holliday 1995 \\
\hline Murzak Koba 1 & Mesolithic & Female & Vančata, in prep. \\
\hline Téviec 1 & Mesolithic & Female & Holliday 1995 \\
\hline
\end{tabular}


Vančata $1988 ; 1993 ; 2003 ; 2005)$ and as a result failed to analyse important adaptive processes in individual periods of human evolution.

2. Another problem concerns the structure of the data examined. The majority of the studies are restricted to investigation of the length of long bones and/or certain basic measurements of the bones (e.g. Frayer 1980; 1981; 1984; Frayer, Wolpoff 1985; Holliday 1997; Jacobs 1985a; 1985b; 1992; Ruff 1987; Ruff et al. 1984; Vančata 1993), and stature reconstruction (Formicolla 1983; 1993; Formicolla; Franceschi 1996; Formicolla; Giannecchini 1999; Jacobs 1993). Such studies can only deal with particular problems, but do not allow for the reconstruction of the most important ecological and life history parameters of an ancient population. Studies providing complex information on the body size and body shape are still exceptional (Ruff et al. 1997; Vančata 1997) and are limited by the number of Neolithic populations examined.

\section{Material}

We have studied femora, tibiae, humeri and radii of the European Upper Palaeolithic population (Pre-Glacial Maximum group - PGM) composed of 24 males, 14 females and 5 individuals of unknown sex, see Table 1; for more details see the papers by: Holliday 1995; 1997; Ruff et al. 1997; Trinkaus, Jelinek 1997; Vančata 1991; 1993; 1997), the Late Upper Palaeolithic group - LUP (19 males, 13 females and 3 individuals of unknown sex, see Table 2), European Mesolithic skeletons (9 males and 6 females, see Table 2) and also those of five Neolithic populations with two types of economy: early Central European agriculturalist populations: Jena, Germany - the Linear Band Pottery Culture - LBPC (32 individuals) and early Central European pastoral populations from Złota, Poland - the Corded Ware Culture CWC (62 individuals) and Jena, Germany - the Corded Ware Culture (38 individuals), and agriculturalist populations from Cujavia, Poland - the Lengyel Culture (45 individuals) and Hungary - the Lengyel Culture (84 individuals) (see Table 3).

The material and data used were selected according to the program of reconstruction of the body size and body shape of fossil Homo sapiens. We have studied the length of the bones and various other measurements of the lower and upper limb long bones (for a methodological approach see: Vančata 1988; 1991; 1997), which enabled us to perform a detailed analysis of the robusticity and biomechanical structure of the lower and upper limb long bones.

The archaeological context for Palaeolithic and Mesolithic materials has been studied in detail and is described extensively in the anthropological and archaeological literature (see references in Tables 1 and 2). The archaeological context of the materials pertaining to Neolithic populations (including, dating, chronological and cultural classification) can be found in publications by Bach (1965; 1978); Bach, Bach (1981); Bogucki (1982; 1988); Czerniak (1980; 1994); Éry (1998); Grygiel, Bogucki (1997); Kruk, Milisauskas (1999); Krzak (1976; 1989); Jankowska et al. (1999); Machnik (1979); Milisauskas, Kruk (1989); Tabaczyński (1970); Zvelebil (1995; 2001); Zvelebil, Lillie (2000).

\section{Methods}

In our pilot study the body size parameters, length of bones and selected measurements and indexes referring to femur, tibia, humerus and radius (see Vančata 1988; 1991; 1993; 1997 for the used methods) were examined for the first time for the following five groups from the transitional period: PGM Upper Palaeolithic Homo sapiens, LUP Upper Palaeolithic Homo sapiens, Mesolithic Homo sapiens, Neolithic early agriculturalist populations and Neolithic early pastoral populations (Table 4). The results were also compared with those of our earlier studies (Vančata 1988; 1991; 1993; 1997; 2003; 2005; Piontek 1999a; 1999b; 2001; Piontek, Vančata 2002; 2004).

\section{Body size and shape reconstruction}

One of the main goals of the study is the reconstruction of the body size and body shape of the Upper Palaeolithic and Neolithic populations. We have estimated the body height and body mass of each examined individual with various regression equations published (e.g., Feldesman et al. 1990; Sjøvold 1990; McHenry 1992; Ruff, Walker 1993). Our

Table 3. Middle European Neolithic populations included in the study.

\begin{tabular}{lcccccc}
\hline Population, country & Culture & N & Males & Females & Studied bones & References \\
\hline Jena, Germany & $\begin{array}{c}\text { Linear Band Pottery Culture } \\
\text { (LBPC) }\end{array}$ & 32 & 13 & 19 & $\begin{array}{c}\text { Humerus, radius, } \\
\text { Femur, tibia }\end{array}$ & $\begin{array}{l}\text { Bach 1978; Bach, Bach 1981; } \\
\text { Vančata 1988; 1993; 1997 }\end{array}$ \\
\hline \begin{tabular}{l} 
Jena, Germany \\
\hline Corded Ware Culture \\
(CWC)
\end{tabular} & 38 & 19 & 19 & $\begin{array}{c}\text { Humerus, radius, } \\
\text { Femur, tibia }\end{array}$ & Bach, Bach 1981 \\
\hline $\begin{array}{c}\text { Corded Ware Culture } \\
\text { Hungary }\end{array}$ & 62 & 33 & 29 & $\begin{array}{c}\text { Humerus, radius, } \\
\text { femur, tibia }\end{array}$ & $\begin{array}{l}\text { Vančata 1988; 1993; 1997; } \\
\text { Krenz-Niedbała 2000 }\end{array}$ \\
\hline Kujavia, Poland & Lengyel Culture (LC) & 84 & 37 & 47 & $\begin{array}{c}\text { Humerus, radius, } \\
\text { femur, tibia }\end{array}$ & Database by Éry 1998 \\
\hline
\end{tabular}


Table 4. List of examined traits.

\begin{tabular}{|c|c|c|}
\hline No. & Variable code & Name of variable \\
\hline 01 & HEADBRTH & Femur - medio-lateral head breadth \\
\hline 02 & NECKLNGH & Femur - neck length \\
\hline 03 & NCKLGBOI & Femur - biomechanical neck length \\
\hline 04 & PRXEPIML & Tibia - medio-lateral diameter of proximal tibia diaphysis \\
\hline 05 & SUBTROAP & Femur - anterio-posterior subtrochanteric diameter \\
\hline 06 & SUBTROML & Femur - medio-lateral subtrochanteric diameter \\
\hline 07 & DIAMDLAP & Femur - anterio-posterior diameter of midshaft \\
\hline 08 & DIAMDLML & Femur - medio-lateral diameter of midshaft \\
\hline 09 & INTEREPI & Tibia - Bicondylar width \\
\hline 10 & TDML & $\begin{array}{l}\text { Tibia-medio-lateral diameter of distal tibial joint surface }(\mathrm{TH}) \text {, it can be also computed by subtracting of } \\
\text { medio-lateral breadth of maleolus medialis from of medio-lateral diameter of distal tibial epiphysis }\end{array}$ \\
\hline 11 & TAPM & $\begin{array}{l}\text { Tibia - middle anterio-posterior diameter of distal tibial joint surface }(\mathrm{TH}) \text {, it can be also computed as } \\
\text { a mean of lateral anterio-posterior diameter of distal tibial joint surface and medial anterio-posterior } \\
\text { diameter of distal tibial joint surface }\end{array}$ \\
\hline 12 & MIDSHAFT & $\begin{array}{l}\text { Tibia - midshaft product (product of medio-lateral diameter of midshaft and anterio-posterior diameter of } \\
\text { midshaft) }\end{array}$ \\
\hline 13 & SUBTROCH & $\begin{array}{l}\text { Femur - subtrochanteric product (product of medio-lateral subtrochanteric diameter and anterio-posterior } \\
\text { subtrochanteric diameter) }\end{array}$ \\
\hline 14 & DISTFEM & $\begin{array}{l}\text { Femur and Tibia - distal tibial products - product of bicondylar width and anterio-posterior of the distal } \\
\text { femoral shaft }\end{array}$ \\
\hline 15 & PROXTIB & $\begin{array}{l}\text { Tibia - proximal tibial product - product of anterio-posterior diameter of proximal tibial epiphysis and } \\
\text { medio-lateral diameter of proximal tibial }\end{array}$ \\
\hline 16 & DISTATIB & $\begin{array}{l}\text { Tibia - distal tibial product - product of medio-lateral diameter of distal tibial joint surface and middle } \\
\text { antero-posterior diameter of distal tibial joint surface (can be calculated from computed values or from } \\
\text { measured values (Holliday, 1995) }\end{array}$ \\
\hline 17 & $\mathrm{~s}-\mathrm{BMI}$ & Skeletal Body mass index (s-BMI=body mass $[\mathrm{g}] /$ height $\left.[\mathrm{cm}]^{2}\right)$ \\
\hline 18 & $\mathrm{~s}$ - Rohrer & Skeletal Rohrer's index (s-Rohrer=body mass $[\mathrm{g}] /$ height $[\mathrm{cm}]^{3}$ ) \\
\hline 19 & Body height & Mean body height estimate from 8 regression (see Table 5 for details) \\
\hline 20 & Body mass & Mean body height estimate from 26 regression equations (see Table 6 for details) \\
\hline
\end{tabular}

approach has, however, several specific features, based on the view that there is no ideal formula for computing body height and body mass, and that the preciseness of the estimates cannot be consistently checked in fossil hominid samples:

1. The body height and body mass are reconstructed by the stochastic approach and should be computed for each skeleton examined.

2. We have not only studied the body height and body mass but also their relation as expressed by skeletal ponderal indexes; Rohrer's body mass index has been used in this study.
3. All body size parameters should also be examined in relation to limb proportions ( $c f$. also Vančata 1996; 1997; 2000). Such an analysis provides us with important and complete information on the body build of the fossil Homo sapiens populations.

Unlike in other studies (see Formicolla; Franceschi 1996; Formicolla, Giannecchini 1999; Sjøvold 1990 for the review), we have computed body parameters as mean values based on several reliable equations, with them being calculated by the same methods for each individual. While in some cases the precision of the estimates of individual body height and body

Table 5. Selected equations for estimates of body height (average values of body height were computed for each individual from the below listed eight equations for the estimate of body height from femoral length and humerus length).

\begin{tabular}{lll}
\hline \multicolumn{1}{c}{ Reference } & \multicolumn{1}{c}{ Parameter } & \multicolumn{1}{c}{ Equations } \\
\hline Feldesman et al.1989; 1990 & Length of femur & $\mathrm{BH}=3.745 \times$ Femur \\
Feldesman, Fountain 1996 & Length of femur & $\mathrm{BH}=3.01939 \times$ Femur +31.26332 \\
Sjøvold 1990 & Length of femur & $\mathrm{BH}=3.10 \times \mathrm{Fem} 2+28.82$ \\
& Length of humerus & $\mathrm{BH}=4.74 \times \mathrm{Hum} 2+15.26$ \\
& Length of femur & $\mathrm{BH}=3.01 \times \mathrm{Fem} 2+32.52$ \\
& Length of humerus & $\mathrm{BH}=4.62 \times \mathrm{Hum} 2+19.00$ \\
Olivier 1976 & Length of femur & $\mathrm{BH}=3.420 \times \mathrm{Fem} 2+17.1$ \\
Jungers 1988 & Length of femur & $\mathrm{BH}=3.8807 \times \mathrm{Fem}-51.0$ \\
\hline
\end{tabular}


Table 6. Selected equations for estimates of body mass (average values of body height were computed for each individual from the below listed 25 equations for the estimate of body mass from femoral and tibial parameters and the body height).

\begin{tabular}{|c|c|c|}
\hline Reference & Parameter & Equations \\
\hline Ruff, Walker 1993 & Stature & $\mathrm{BM}=0.689 \times$ Stat -53.1 \\
\hline Jungers, Stern 1983 & Stature & $\mathrm{BM}=0.00013 \times \operatorname{Stat}^{\wedge} 2.554$ \\
\hline \multirow[t]{2}{*}{ Wolpoff 1983} & Stature & $\mathrm{BM}=0.00011 \times \operatorname{Stat}^{\wedge} 2.592$ \\
\hline & Stature & $\mathrm{BM}=0.00062 \times \operatorname{Stat}^{\wedge} 2.241$ \\
\hline McHenry 1988 & subtrochanteric product & $\log B M=0.624 \times \log \times$ Subtroch -0.0562 \\
\hline \multirow[t]{5}{*}{ McHenry 1991} & femoral head & $\log \mathrm{BM}=1.7125 \times \log \mathrm{Head}-1.048$ \\
\hline & subtrochanteric product & $\log B M=0.7316 \times \log$ Subtroch -0.4527 \\
\hline & distal femoral product & $\log \mathrm{BM}=0.960 \times \log \mathrm{DistFem}-1.5678$ \\
\hline & proximal tibial product & $\log \mathrm{BM}=1.0583 \times \log$ ProxTib- 1.9537 \\
\hline & distal tibial product & $\log B M=0.9005 \times \log$ Subtroch -0.8790 \\
\hline \multirow[t]{15}{*}{ McHenry 1992} & femoral head & $\log B M=1.7125 \times \operatorname{logHead}-1.0480$ \\
\hline & & $\log \mathrm{BM}=1.7754 \times \log \mathrm{Head}-1.1481$ \\
\hline & & $\log B M=1.7538 \times \log H e a d-1.1137$ \\
\hline & subtrochanteric product & $\log B M=0.7927 \times \log$ Subtroch -0.5233 \\
\hline & & $\log B M=0.8069 \times \log$ Subtroch -0.5628 \\
\hline & & $\log B M=0.8107 \times \log$ Subtroch $-0.5 \& 33$ \\
\hline & distal femoral product & $\log B M=0.9600 \times \log$ DistFem -1.5678 \\
\hline & & $\log \mathrm{BM}=0.9919 \times \log$ DistFem -1.6754 \\
\hline & & $\log B M=0.9921 \times \log$ DistFem -1.6762 \\
\hline & proximal tibial product & $\operatorname{logBM}=1.0583 \times \log$ ProxTib-1.9537 \\
\hline & & $\log \mathrm{BM}=1.0689 \times \log$ ProxTib-1.9903 \\
\hline & & $\log B M=1.0683 \times \log$ ProxTib -1.9880 \\
\hline & distal tibial product & $\log \mathrm{BM}=0.9005 \times \log$ DistTib -0.8790 \\
\hline & & $\log \mathrm{BM}=0.9227 \times \log$ DistTib- 0.9418 \\
\hline & & $\log B M=0.9246 \times \log$ DistTib -0.9473 \\
\hline
\end{tabular}

mass obtained with this approach may not be optimal, they should be free of random errors with regard to the estimates of the body size, and thus it is much more appropriate for describing the body size variability within a population.

Body height has been computed with the MA and RMA formulas published by Feldesman and colleagues (Feldesman et al. 1989; 1990; Feldesman, Fountain 1996), Jungers (1988), Olivier (1976) and Sjøvold (1990). We computed the mean values from six equations based on the femoral length and two equations for the humeral length. Humeral formulas are less precise (see Sjøvold 1990) but diminish the influence of random errors connected with unexpected values of femoral length in individuals (Table 5).

We have used 25 formulae computed from the femoral head, subtrochanteric product, distal femoral product and proximal tibial and distal tibial products (McHenry 1988; 1991; 1992). Traditional formulae based on a correlation between body height and body mass (Jungers, Stern 1983; Ruff, Walker 1993; Wolpoff 1983) were also computed in order to minimise random errors caused, for example, by extremely gracile or extremely robust femora and/or tibiae. The resulting body mass has been computed as the mean of those 25 values (Table 6).

Two ponderal indexes - skeletal Body Mass Index (s-BMI) and skeletal Rohrer's index (s-Rohrer) - were computed (see formulae in the List of measurements) for all the specimens studied. They are integral parameters, expressing relations of body linearity, body volume and body mass, as well as general body shape.

The data were managed in QuattroPro 8.0 for Windows table processor with computation carried out by Statistica 10. All the tests were made at a 95\% level of significance.

\section{Morphological changes in the transition to agriculture}

\subsection{The length of long bones and their proportions}

Bone lengths (Figure 1) are the first group of traits revealing important microevolutionary changes in the Upper Palaeolithic/Neolithic transition. There are basically three different groups in the skeletal sample studied: the PGM Upper Palaeolithic group with very extremely long bones, especially particularly in males, the LBPC Neolithic group with very extremely short bones, and finally the group that which consists of the LUP Upper Palaeolithic, Mesolithic and the CWC Neolithic populations with medium-length bones.

However, a comparison of the long bone proportions reveals a somewhat different picture (Figure 2). Both Upper Palaeolithic groups are similar in having a relatively long tibia and radius, while an extremely short tibia and radius are typical of the LBPC Neolithic group are a very short tibia 


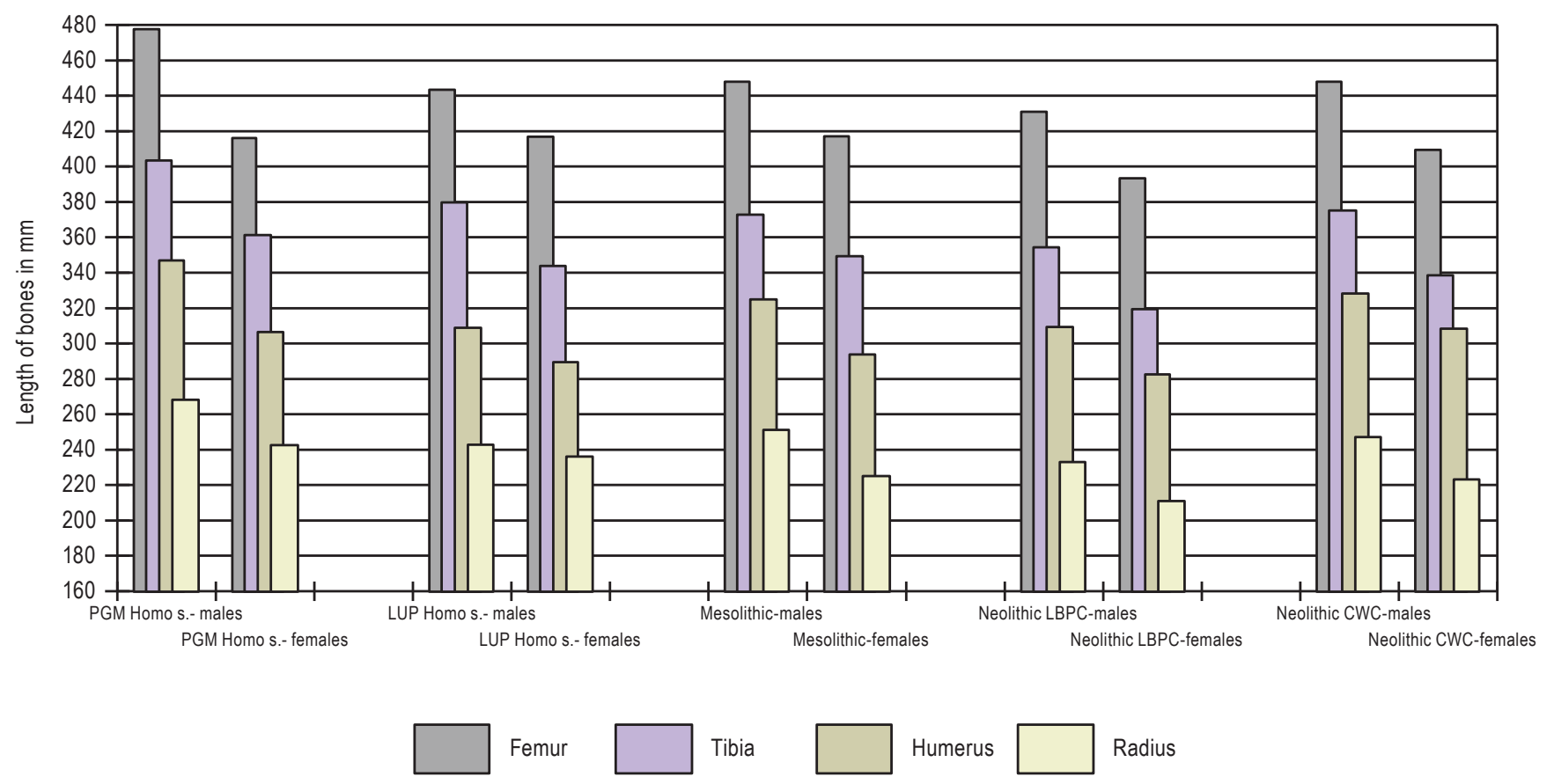

Figure 1. Length of femur, tibia, humerus and radius for Upper Paleolithic, Mesolithic and Neolithic human populations. PGM - Pre-glacial Maximum Upper Paleolithic (Gravettien), LUP - Late Upper Paleolithic, LPBC - Neolithic - Linear Band Pottery Culture, CWC - Neolithic - Corded Ware Culture.

and radius, while and the Mesolithic and CWC Neolithic groups' traits are intermediate between the two. An additional analysis of the long bones and bone proportionality of the five Neolithic populations (Figures 3, 4) confirms this conclusion. However, the differences primarily hold true for populations occupying the same geographic region.

\subsection{Robusticity and morphological patterns of the long bones}

The results of the analysis of the robusticity and proportionality of individual bones (Figures 5-8) are more complex, but are basically consistent with the above schemes. The results can be divided into the following three topics: 1) Morphology

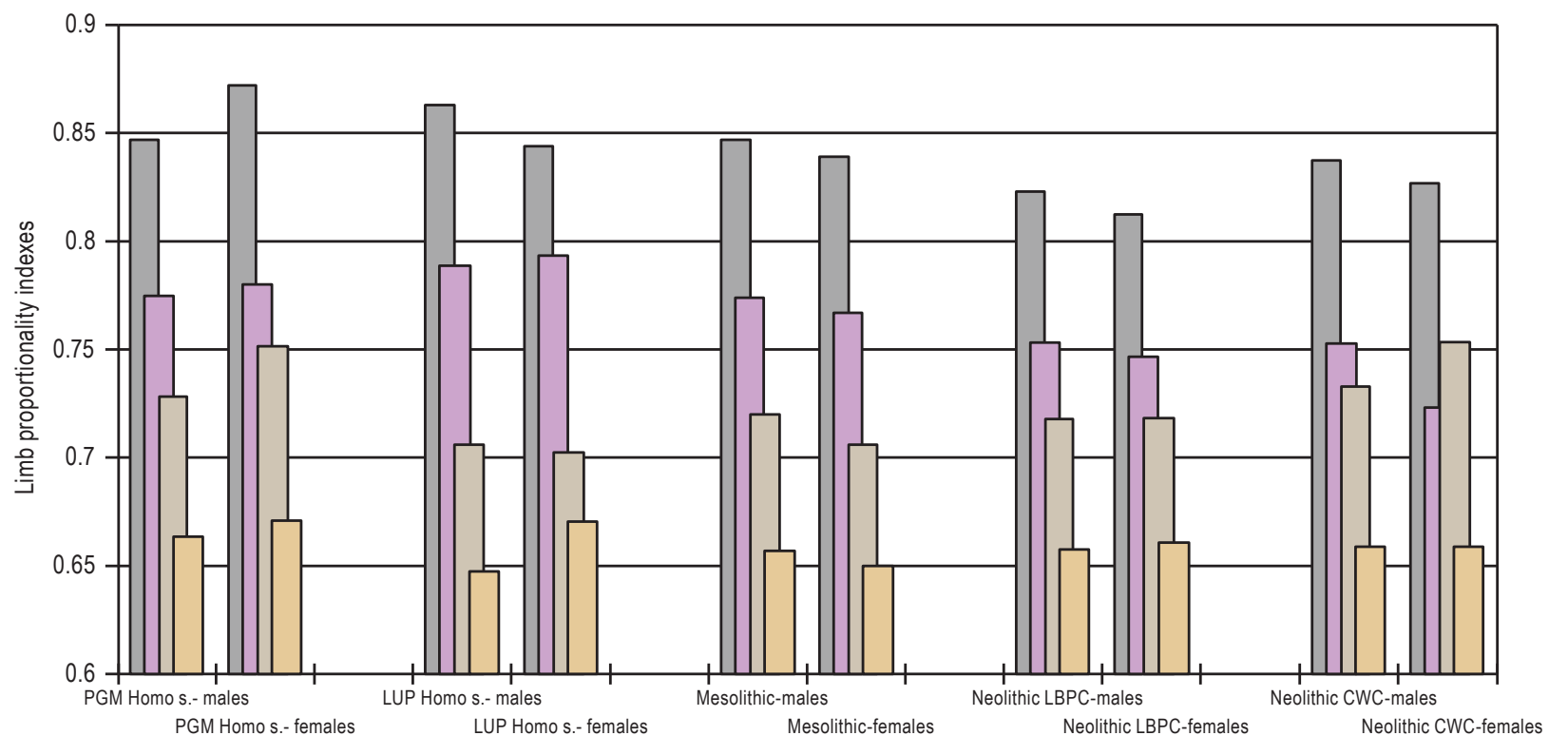

CRURAL

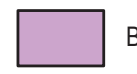

BRACHIAL

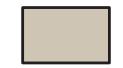
HUMFEMIN RADTIBIN

Figure 2. Basic limb proportions for Upper Paleolithic, Mesolithic and Neolithic human populations. PGM - Pre-glacial Maximum Upper Paleolithic (Gravettien), LUP - Late Upper Paleolithic, LPBC - Neolithic - Linear Band Pottery Culture, CWC - Neolithic - Corded Ware Culture. 


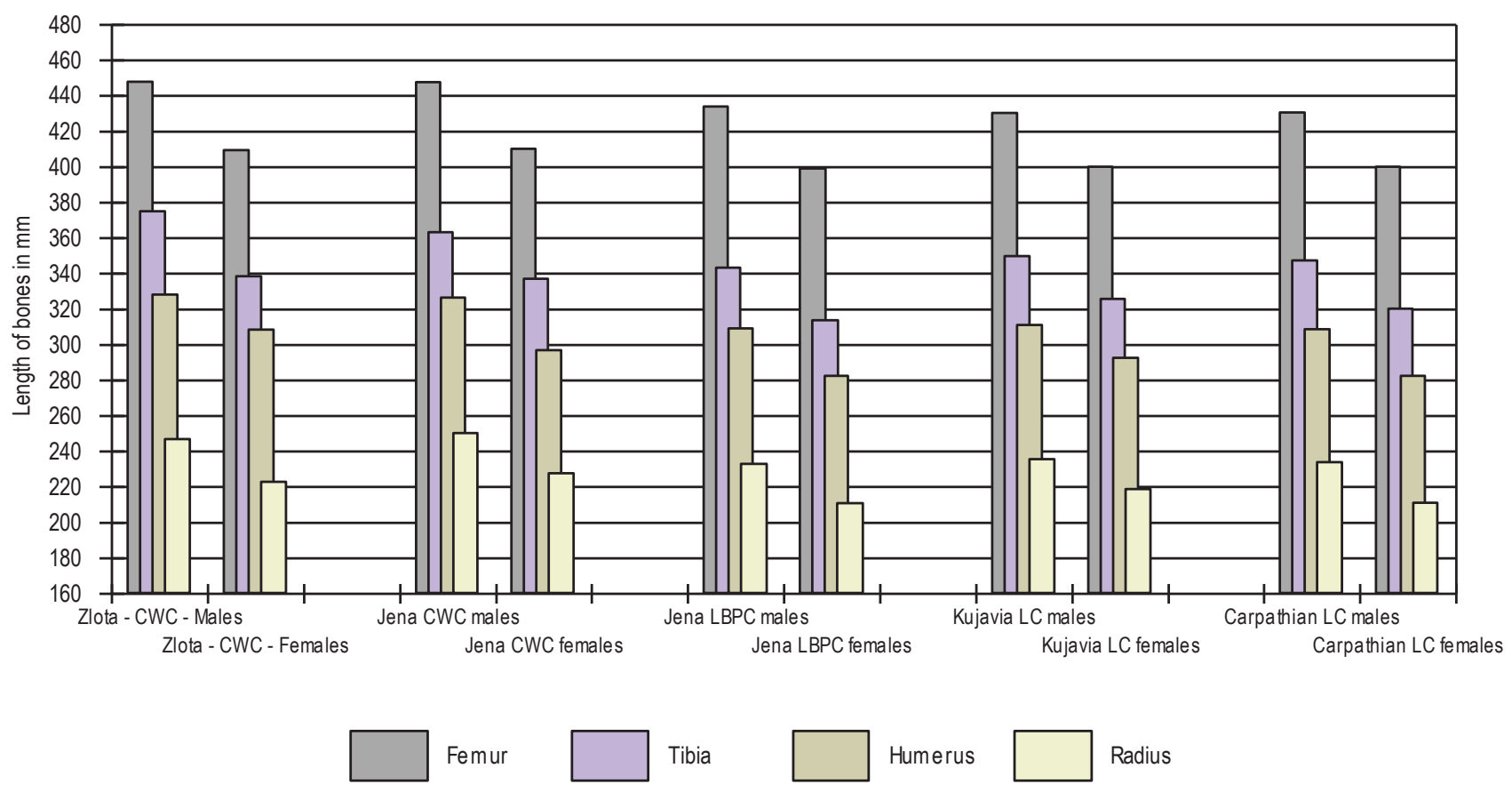

Figure 3. Length of femur, tibia, humerus and radius for selected Neolithic human populations. LPBC - Neolithic - Linear Band Pottery Culture, CWC Neolithic - Corded Ware Culture, LC - Neolithic - Lengyel Culture.

and proportionality of the long bones epiphyses, 2) The shape of the femoral diaphysis and size relations, and 3) The shapes of individual femoral and tibial epiphyses and their relations.

1. Both Upper Palaeolithic groups have a relatively larger femoral head and shorter femoral neck, while the Neolithic ones have an extremely very long femoral neck and a relatively smaller femoral head (Figures 5-8). The Mesolithic group is intermediate in this respect. Both Upper Palaeolithic and Mesolithic groups have generally more robust distal femoral and proximal tibial epiphyses in comparison with both Neolithic populations. However, this holds mainly true for Neolithic females, and there are differences among the Neolithic populations studied.

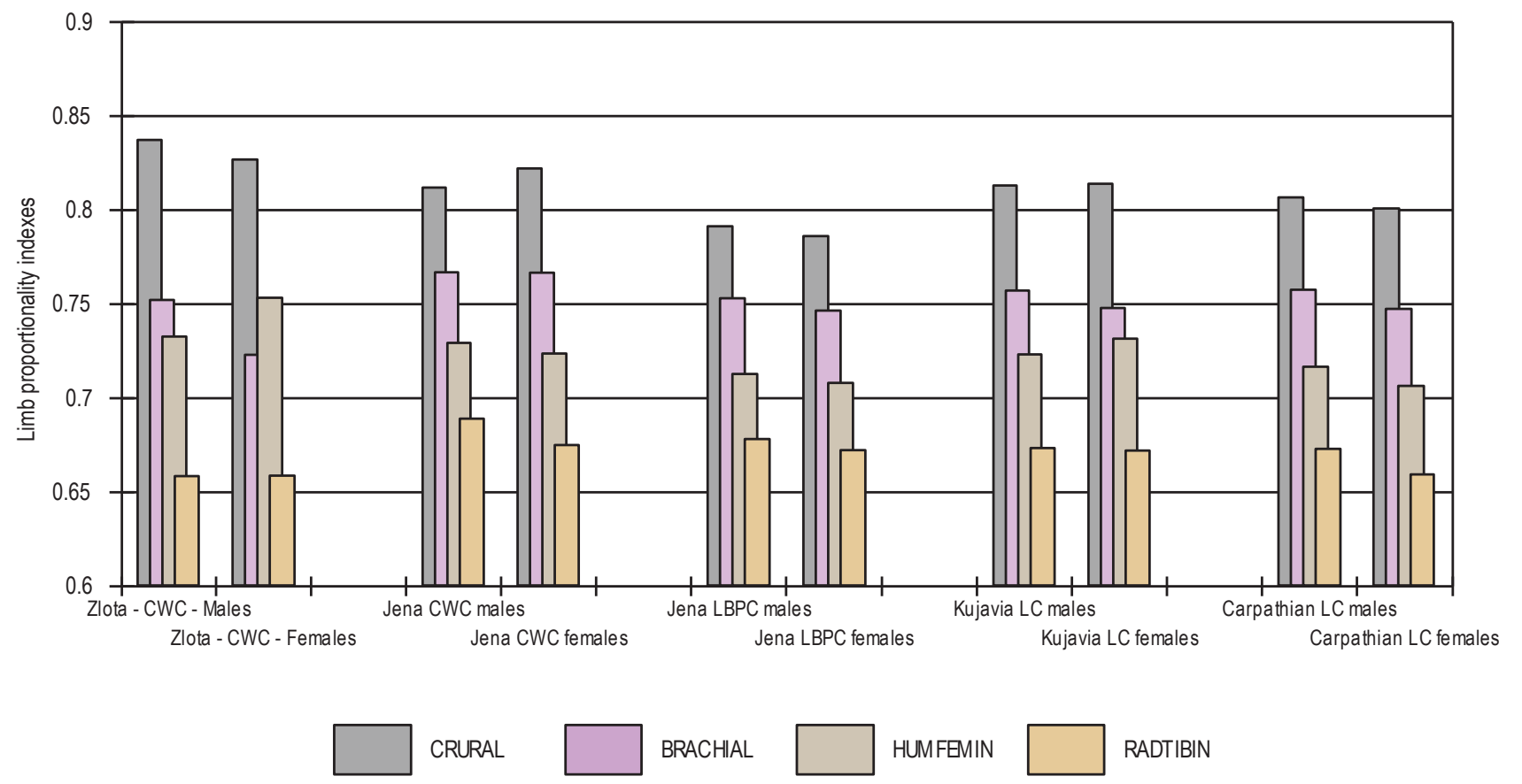

Figure 4. Basic limb proportions for selected Neolithic human populations. LPBC - Neolithic - Linear Band Pottery Culture, CWC - Neolithic - Corded Ware Culture, LC - Neolithic - Lengyel Culture. 


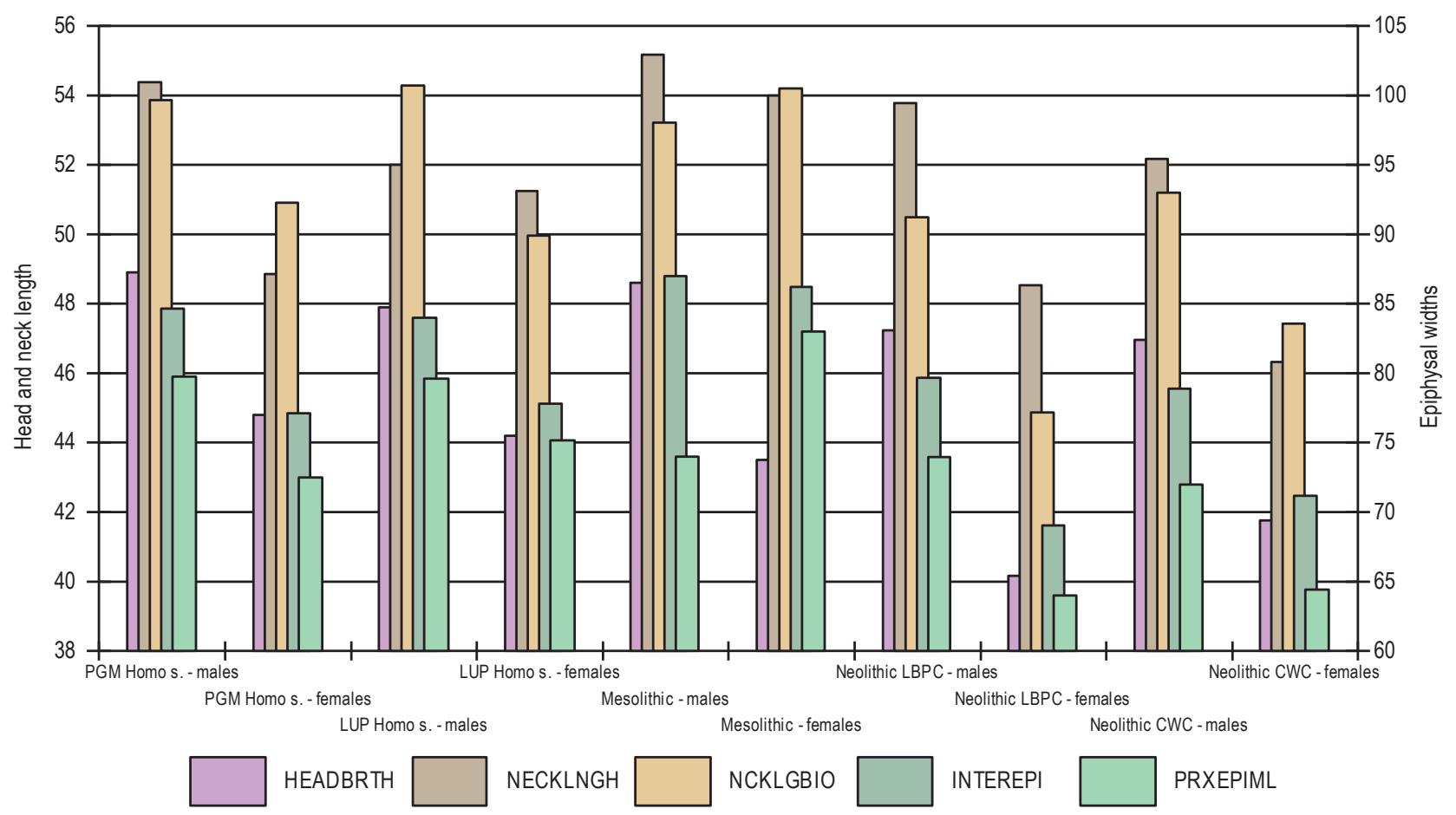

Figure 5. Head breadth, neck length and width parameters of femur and tibia for Upper Paleolithic, Mesolithic and Neolithic human populations. PGM Pre-glacial Maximum Upper Paleolithic (Gravettien), LUP - Late Upper Paleolithic, LPBC - Neolithic - Linear Band Pottery Culture, CWC - Neolithic - Corded Ware Culture.

The distal tibial epiphysis is more robust in Neolithic populations in comparison with the Upper Palaeolithic and Mesolithic ones, although it is much more robust in the LBPC Neolithic group than in the CWC Neolithic group.
2. UpperPalaeolithicgroupsusuallyhaveaflatsubtrochanteric region and a rounded femoral diaphysis with a prevailing sagittal diameter (drop-shaped cross-section) while the Neolithic populations have a rounded subtrochanteric region and a more gracile femoral diaphysis (Figures 6, 7).

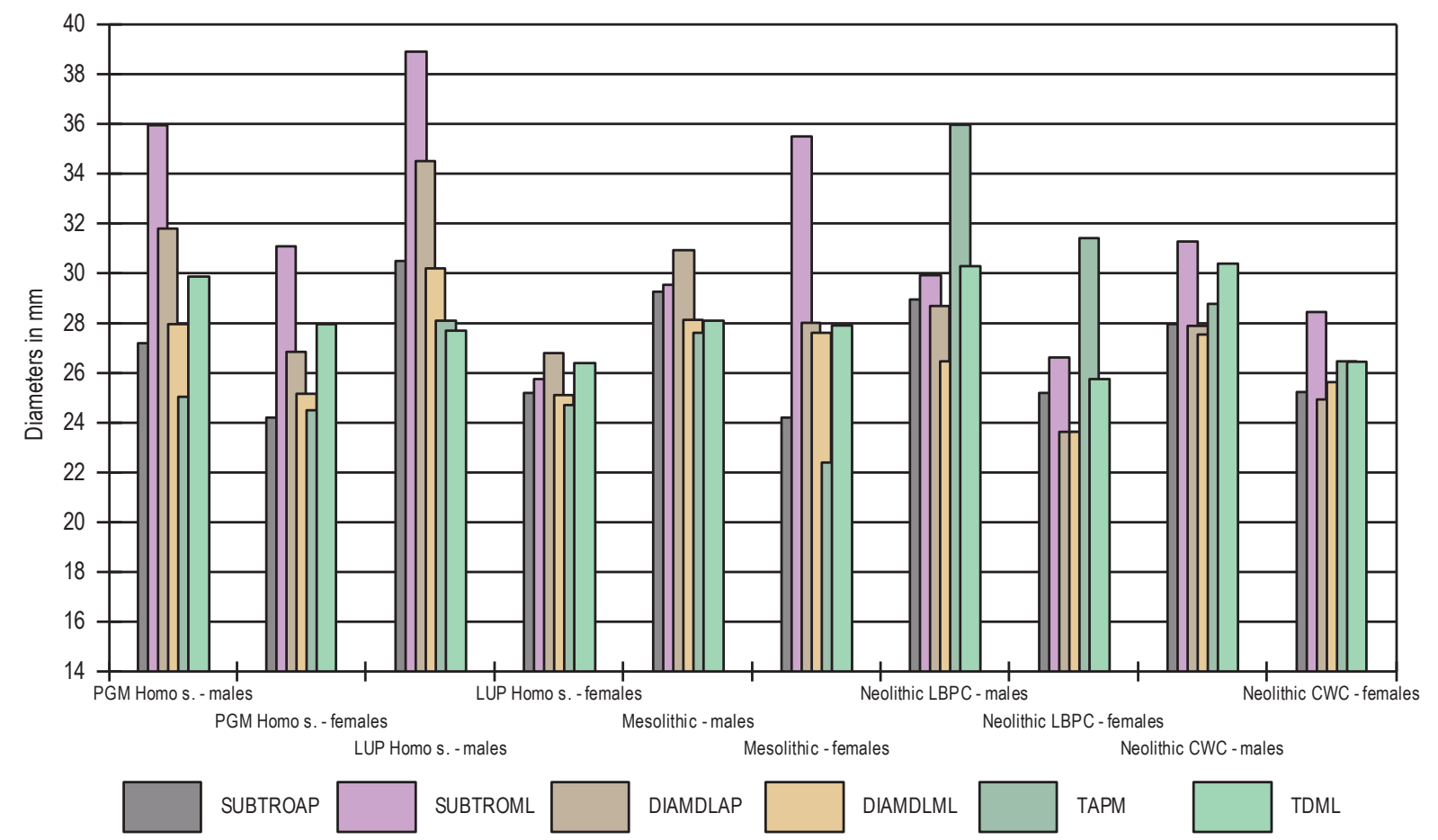

Figure 6. Important diameters of femoral diaphysis and distal tibial joint surface for Upper Paleolithic, Mesolithic and Neolithic human populations. PGM - Pre-glacial Maximum Upper Paleolithic (Gravettien), LUP - Late Upper Paleolithic, LPBC - Neolithic - Linear Band Pottery Culture, CWC - Neolithic - Corded Ware Culture. 


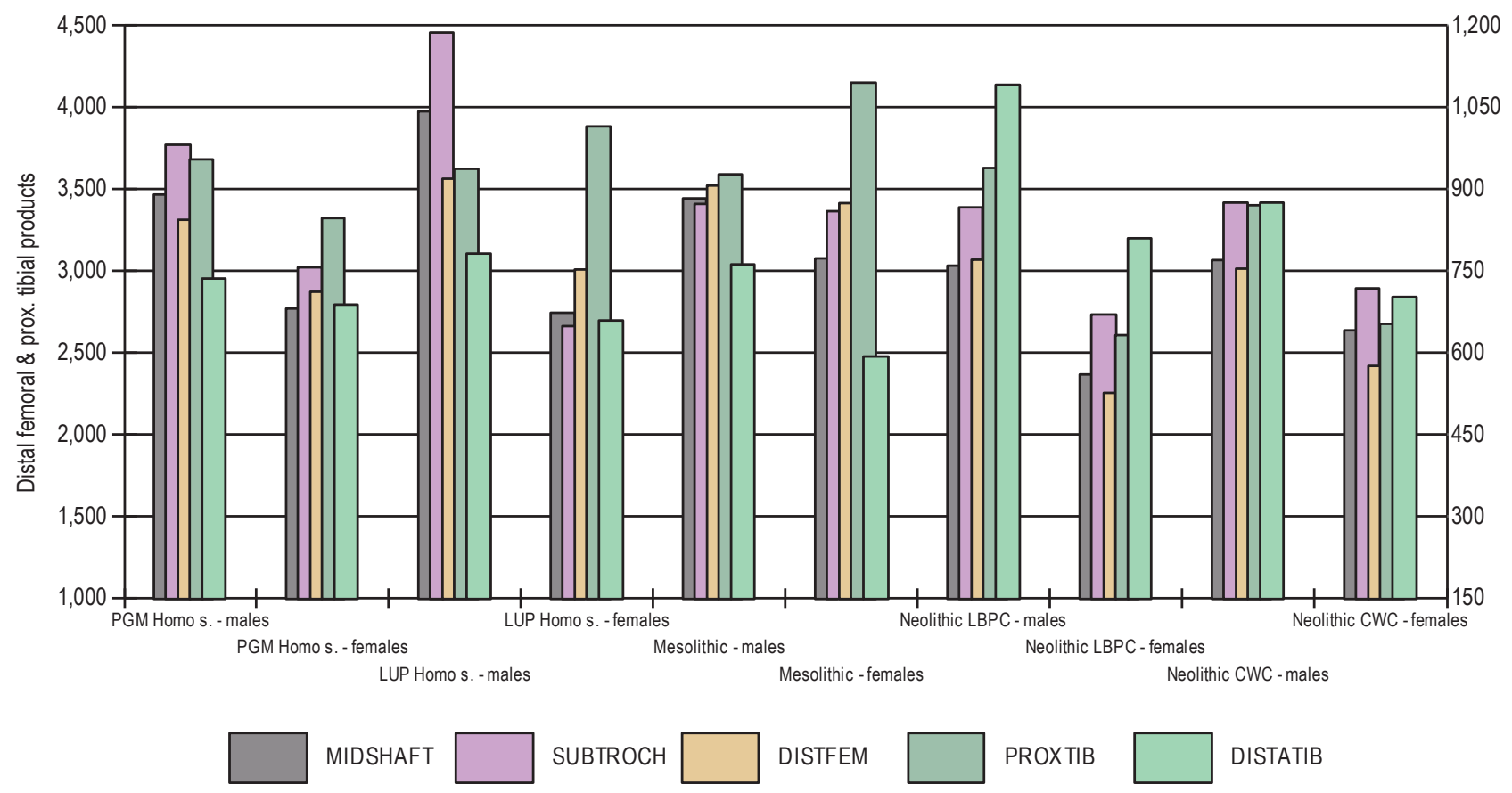

Figure 7. Five most important product of femur and tibia for Upper Paleolithic, Mesolithic and Neolithic human populations representing approximation to the cross-sectional surface sensu McHenry 1991. PGM - Pre-glacial Maximum Upper Paleolithic (Gravettien), LUP - Late Upper Paleolithic, LPBC Neolithic - Linear Band Pottery Culture, CWC - Neolithic - Corded Ware Culture.

In the Mesolithic group the traits seem to be intermediate compared with those of the two other groups.

3. The most remarkable differences among the groups are observed in the proximal femoral and the distal tibial epiphyses (Figures 5, 6, 8). The Upper Palaeolithic groups have a relatively large femoral head in relation to the femoral neck and have a relatively large biomechanical neck length. The Neolithic populations are characterized by a relatively small femoral head in relation to the femoral neck, an extremely long femoral neck and a

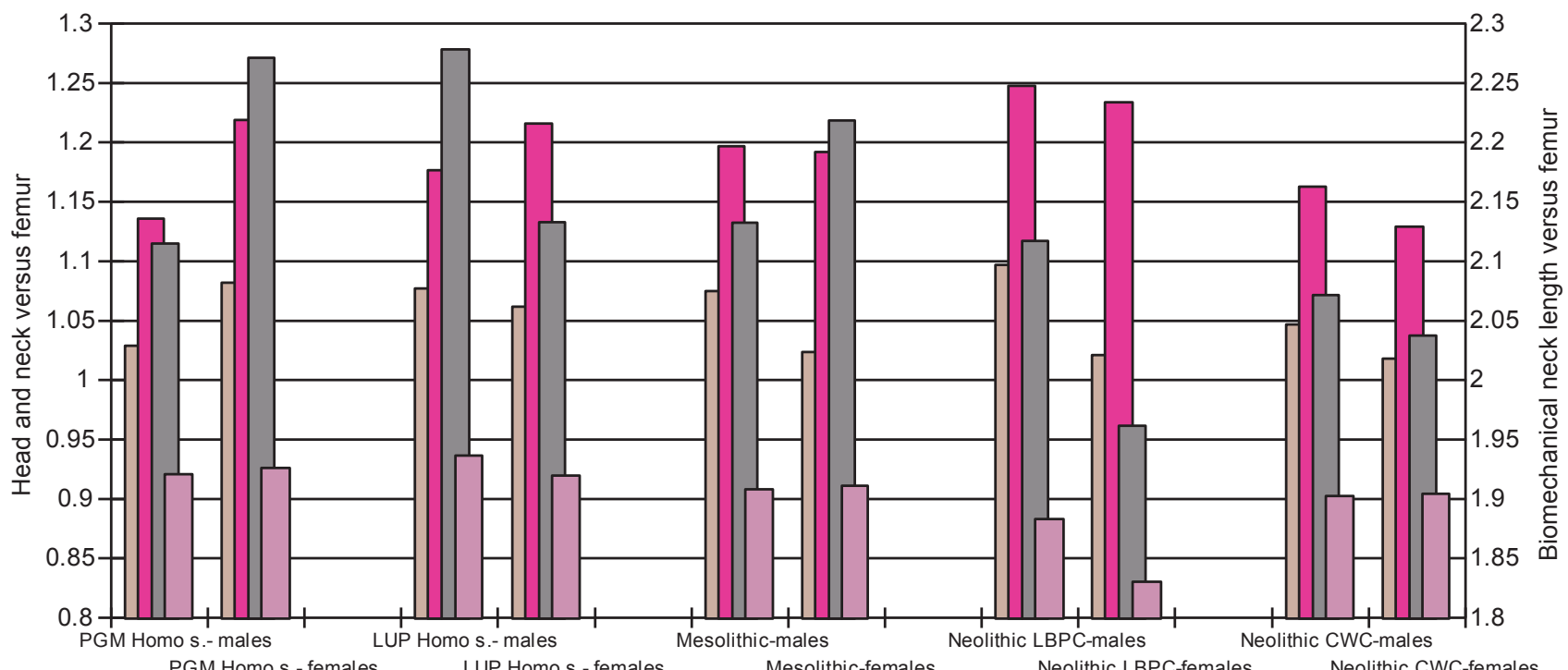

Head / Femur

Neck / Femur

Biom.neck/Femur

Head / Neck

Figure 8. Selected indexes representing proportionality of proximal femoral epiphysis and femur for Upper Paleolithic, Mesolithic and Neolithic human populations. PGM - Pre-glacial Maximum Upper Paleolithic (Gravettien), LUP - Late Upper Paleolithic, LPBC - Neolithic - Linear Band Pottery Culture, CWC - Neolithic - Corded Ware Culture. 
relatively short biomechanical length diameter. This morphological pattern is again much more developed in the LBPC Neolithic group, compared with the CWC one. The Mesolithic group is virtually intermediate with regard to this morphological pattern, which documents particularly well the rebuilding of the proximal femoral epiphysis during the Upper Palaeolithic-Neolithic transition. The shape and size of the distal tibial epiphysis differs markedly between the Upper Palaeolithic and Neolithic groups. While both Upper Palaeolithic groups, just as the Mesolithic one, have a relatively gracile distal tibial epiphysis with a longer sagittal diameter, both Neolithic groups have a more robust distal tibial epiphysis (Figures 6, 7). However, there is again a remarkable difference between the two Neolithic groups. The CWC group has a square-shaped and relatively robust distal tibial epiphysis, while the LBPC group has an extremely robust distal tibial epiphysis with a remarkably prevailing transversal diameter (Figures 6,7).

\subsection{Body size and shape}

Body size in these populations has been examined as a complete parameter represented by the reconstructed body height, body mass and two ponderal indexes (s-BMI and s-Rohrer index). An analysis of the reconstructed body height (Figure 9) indicates that there are basically 3 groups in this area. Relatively tall or even extremely tall individuals are usually found in the Gravettian PGM group, while short or particularly short individuals in the LBPC Neolithic groups, with an intermediate stature in the remaining groups. An analysis of the body mass reveals a similar picture, although there is a remarkable sexual dimorphism in both the Gravettian and the LBPC Neolithic groups. While the PGM females are relatively extremely heavy and males lightly built, in the Neolithic group the situation is completely opposite; the males are extremely heavy and the females extremely light. This situation is much better reflected by the ponderal indexes (Figure 10). While the LUP Upper Palaeolithic, Mesolithic and CWC Neolithic groups have a similar body shape with medium robusticity of the body in both sexes, there are different groups with a particularly marked but specific sexual dimorphism; the Gravettian one with extremely robust females and the LBPC Neolithic one with extremely robust, short males.

\subsection{Sexual dimorphism}

A complete interpretation of the results would be impossible without an analysis of sexual dimorphism. The sexual differences are extremely large both in size and in shape in the Gravettian and LBPC Neolithic populations, on the one hand, and medium to large in size and medium to small in the LUP Upper Palaeolithic, Mesolithic and CWC Neolithic populations on the other.

The PGM Upper Palaeolithic males were tall or very extremely tall and relatively slim, but while females were relatively small and very extremely robust. PGM Upper Palaeolithic females had relatively longer tibia, a longer femoral neck and a relatively larger femoral head than males. The LUP Upper Palaeolithic males were of medium stature and robusticity. They had a longer tibia, biomechanical neck length and a larger femoral head compared with females. In this group, females are significantly smaller than males,

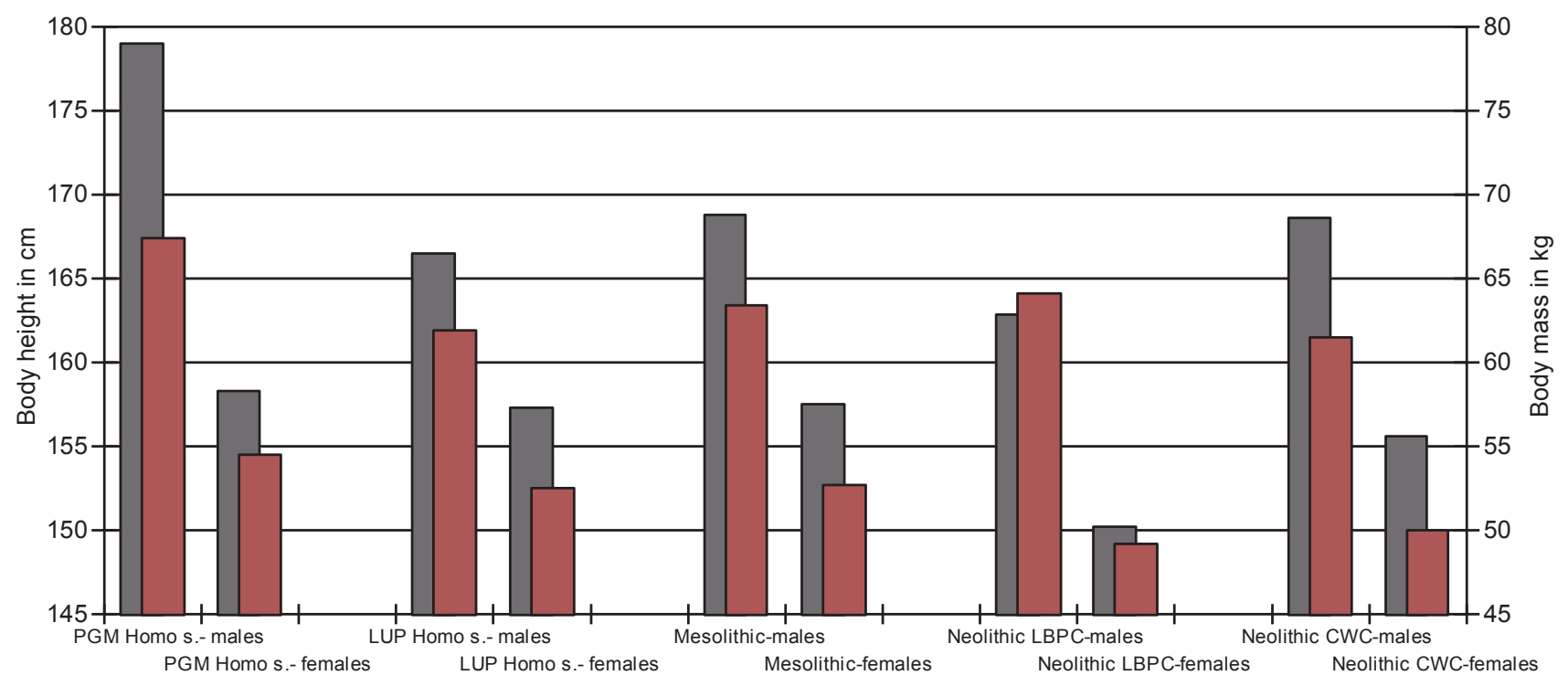

Body height

Body mass

Figure 9. Estimated body height and body mass for Upper Paleolithic, Mesolithic and Neolithic human populations. PGM - Pre-glacial Maximum Upper Paleolithic (Gravettien), LUP - Late Upper Paleolithic, LPBC - Neolithic - Linear Band Pottery Culture, CWC - Neolithic - Corded Ware Culture. 


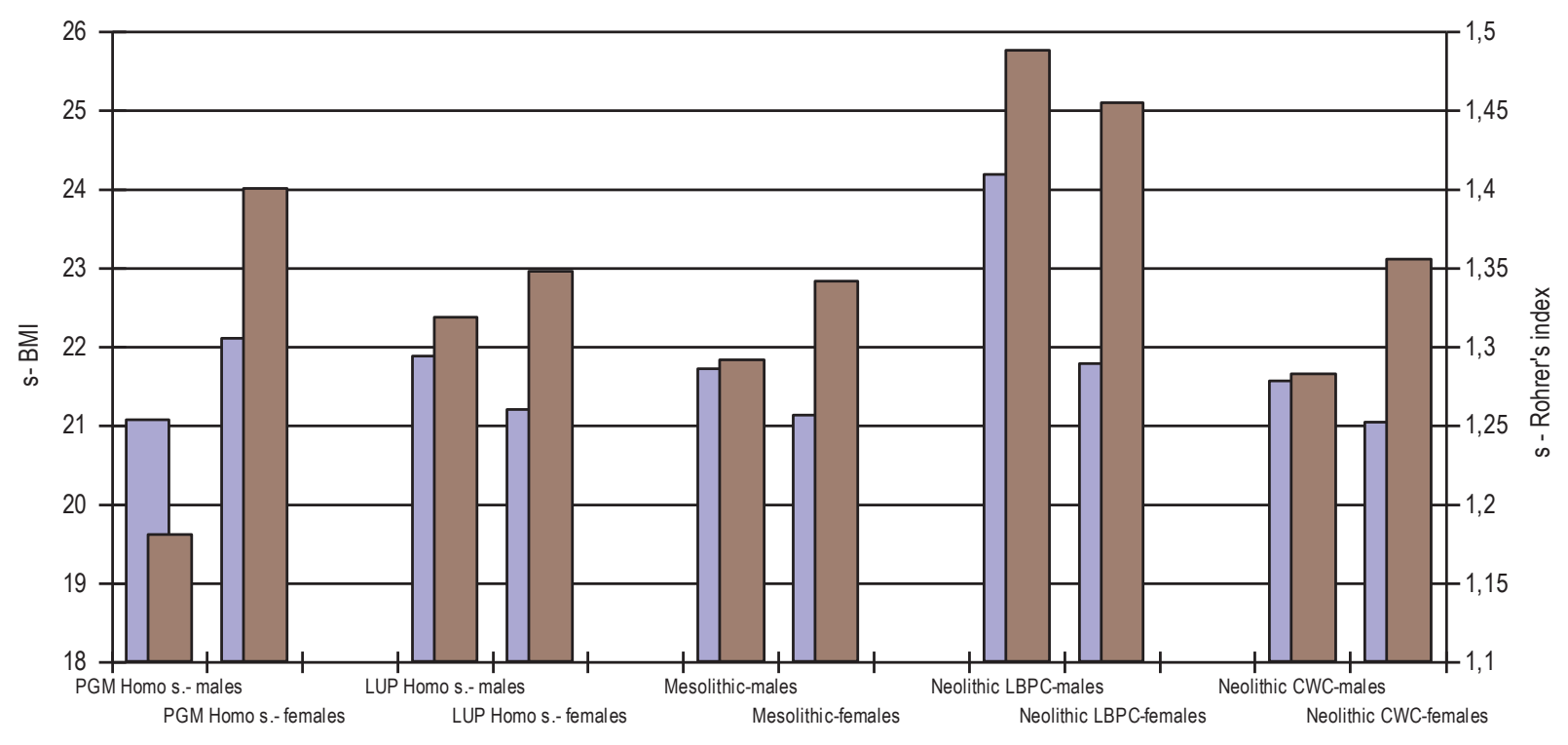

S - BMI

s - Rohrer

Figure 10. Skeletal ponderal indexes for Upper Paleolithic, Mesolithic and Neolithic human populations. PGM - Pre-glacial Maximum Upper Paleolithic (Gravettien), LUP - Late Upper Paleolithic, LPBC - Neolithic - Linear Band Pottery Culture, CWC - Neolithic - Corded Ware Culture.

they have a relatively longer femoral neck and more robust proximal tibia. However, the degree of sexual dimorphism in this population is much lower compared with that of the PGM Upper Palaeolithic group.

Mesolithic males' and females' general body size and shape are quite similar to those of the LUP Upper Palaeolithic group. Some differences can be found between the LUP and the Mesolithic females. Mesolithic females have more robust bones with a longer femoral neck. They have a relatively much longer femoral neck and biomechanical neck length, more robust subtrochanteric region, distal femoral epiphysis and a much more robust proximal tibial epiphysis in comparison with Mesolithic males.

The two Neolithic groups are extremely different in the degree and character of sexual dimorphism.

The CWC Neolithic group from Złota is fairly similar to the Mesolithic one. Males have a medium stature and are not particularly robust. Females are significantly smaller than males, but do not differ from the CWC males in terms of robusticity and proportions. All the sexual differences, both in the body build and in bone morphology and proportions seem to be in size, rather than in the shape of the body or bones.

The LBPC Neolithic group has an extremely high degree of sexual dimorphism with regard to both size and shape. Females and males are both significantly more robust than those in the CWC group. The LBPC females are extremely small and more gracile than the males. They have relatively longer upper limbs and femoral necks, and relatively smaller femoral heads in comparison with the males. The latter have generally more robust bones, particularly their proximal femoral epiphyses and distal tibial epiphyses, which are much larger than those of the LBPC females.

\section{The transition to agriculture: a general model and hypothesis}

The emergence of agriculture and its subsequent spread across Europe and other continents has been modelled in a variety of ways. In our view two theoretical approaches deserve special attention. Both describe the role of social and economic factors in the shaping of the biological structure of early agricultural populations (Hassan 1973; 1978; 1979; 1981; Larsen 1987; 1990; 1995).

Hassan (1981) proposed a demographic model for the transition to agriculture. In this model he considered the higher fertility rate to be an essential factor in the principal transformations of the biological structure of early agricultural populations (Figure 11). He also suggested that a high fertility rate must have been related to early marriage (that is, to an early start-of-reproduction by women in farming populations). Hassan's (1981) suggestions have been corroborated by demographic studies of the fertility rate in modern traditional farming communities. In a cross-cultural demographic study (31 traditional agriculturalist and 26 non-agriculturalist populations), Bentley etal. (1993) demonstrated that higher fertility was primarily associated with the intensification of agriculture (Figure 12).

Similar suggestions were put forth by Larsen (1987; 1990; 1995). In his model of agricultural transition he viewed early puberty as a major factor influencing body shape and size in early agriculturalists. However, he associated the change in growth patterns in early farming populations with changes in the living conditions following the transition to agriculture (Figure 13). 


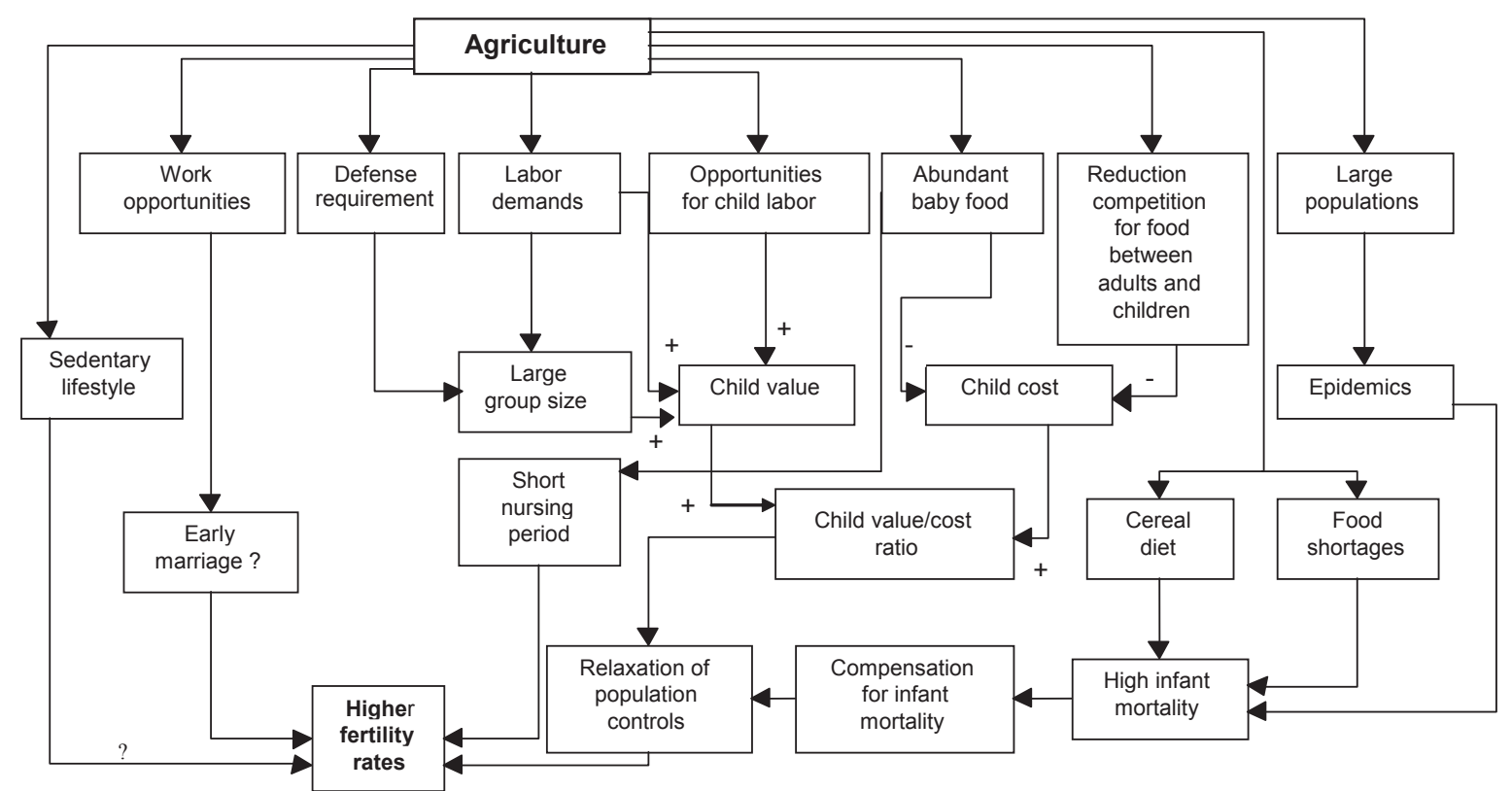

Figure 11. A model of the impact of agriculture on the determinants of fertility (Hassan 1981: 228).

Similarly, Trinkaus and Tompkins (1990) presented interesting data on the differences between populations of hunter-gatherers and traditional agriculturists at the age when girls reached menarche and at the age of first reproduction (Figure 14). The data indicate that girls in hunter-gatherer populations reached menarche on average 3 years later (at the age of 16) than girls in traditional agriculturalist populations (at the age of 13). Also the starting age of reproduction in hunter-gatherers was on average as late as 19 years, whereas it occurred at 18 years in traditional agriculturists.
From the above, early puberty and an associated early start of reproduction in Neolithic agricultural populations could have resulted in differential reproduction, and thus a shift in selection pressures favouring early maturing individuals.

Following Hassan's $(1973 ; 1978 ; 1979 ; 1981)$ and Larsen's (1987; 1990; 1995) approaches, in 1999 we presented a processual model of skeletal adaptation and long bones changes in the transition to agriculture (Piontek 1999a; 1999b; 2001). In this model we proposed that the biological consequences of the Neolithization process should

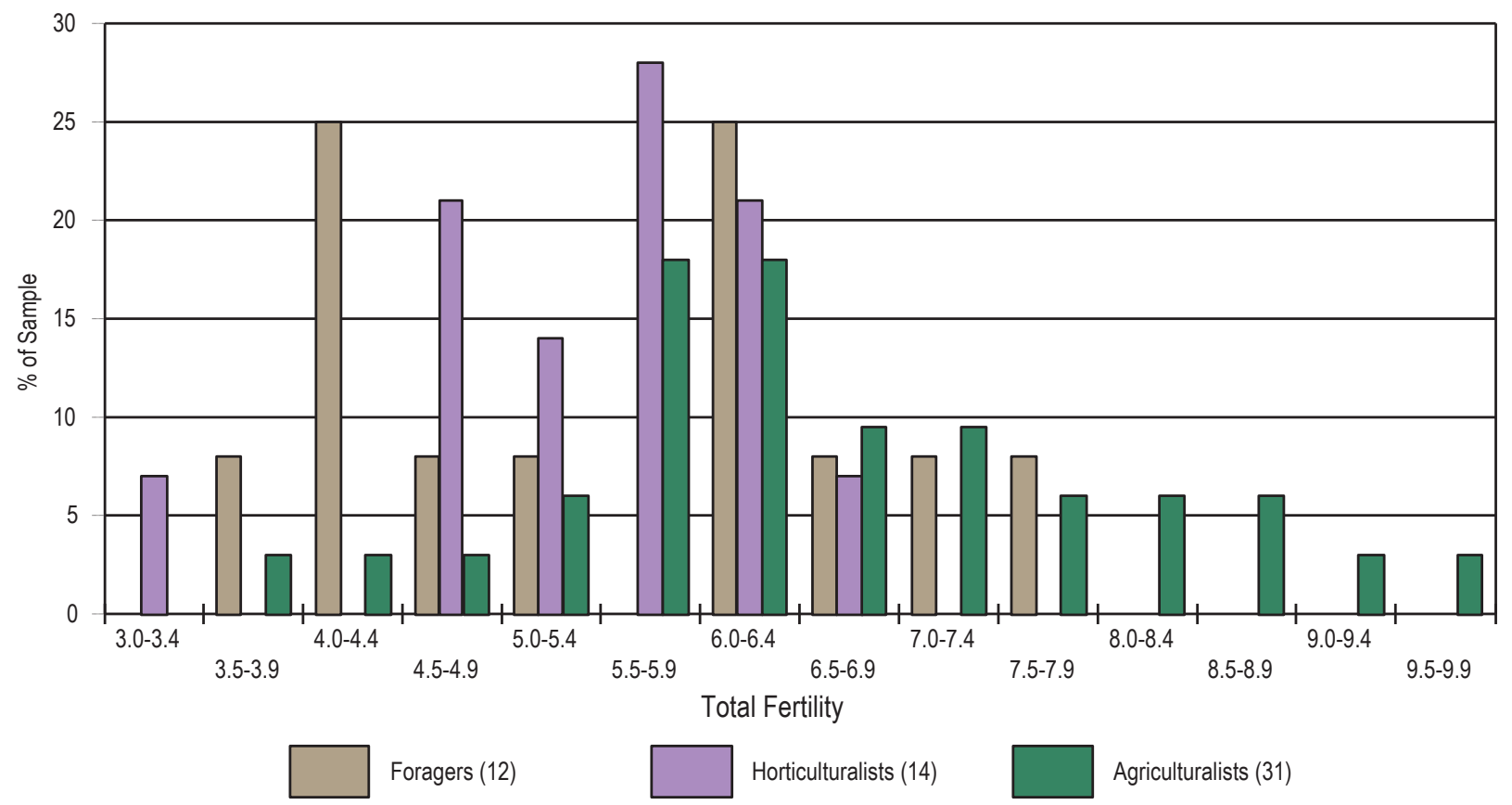

Figure 12. Comparison of the percentage distributions of total fertility between foraging, horticultural and agricultural populations (Bentley et al. 1993). 


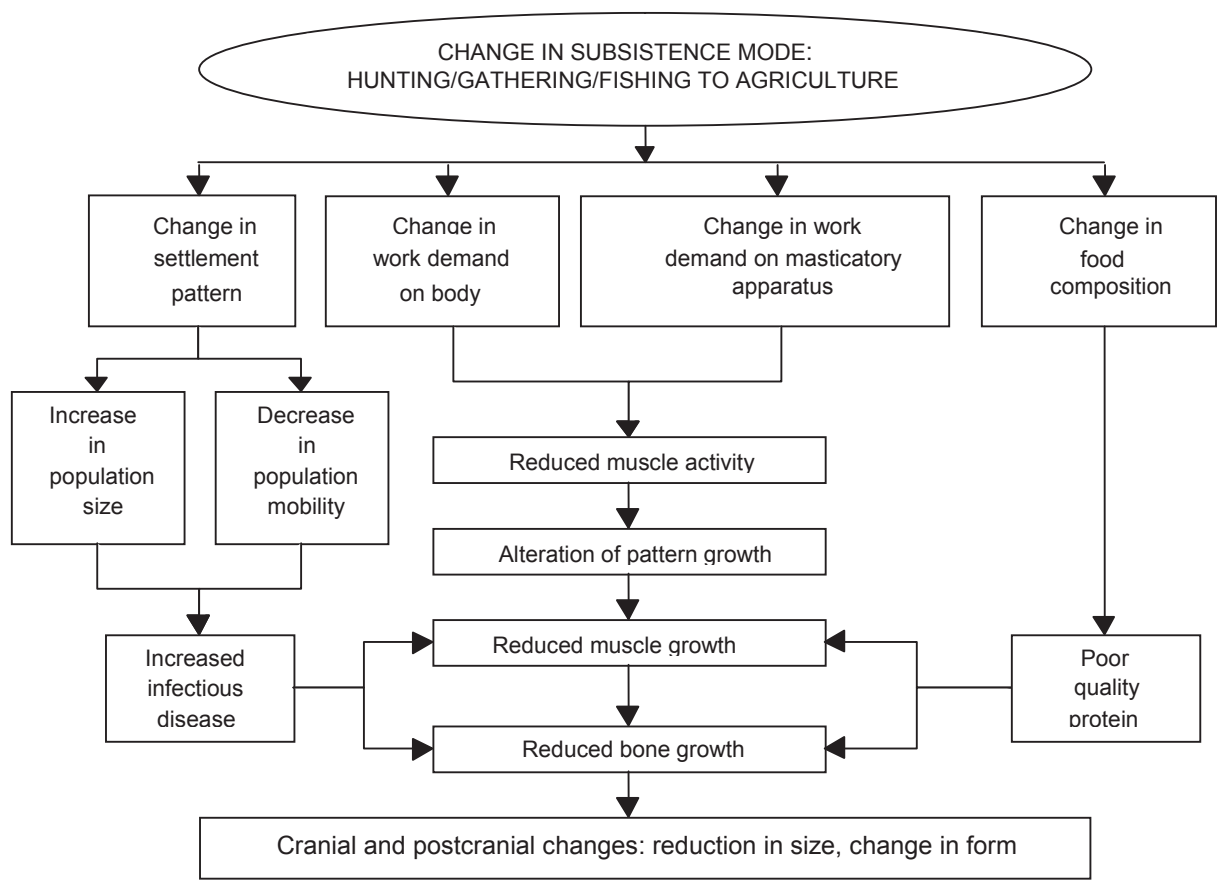

Figure 13. Processual model of biocultural adaptation on the prehistoric Georgia coast (Larsen 1987; 1995).

be analysed as an outcome of the influence of two groups of biological and sociocultural factors on early agriculturalist populations (Figure 15). We concluded that:

1. In agreement with Larsen's suggestions (1987; 1995), a new adaptive strategy followed by Neolithic populations had brought about a change in the orientation of adaptive processes influencing individuals' biological responses to new types of socio-economic factors, such as: dietary change, increased infection, disease, opportunity for child labour, etc.

2. New adaptive strategy closely connected with a significant transformation of the demographic structure of early agricultural populations potentially favoured, via the differential fertility of early and late maturating individuals (given the context of the high fertility rate), the rapid development of individuals with earlier

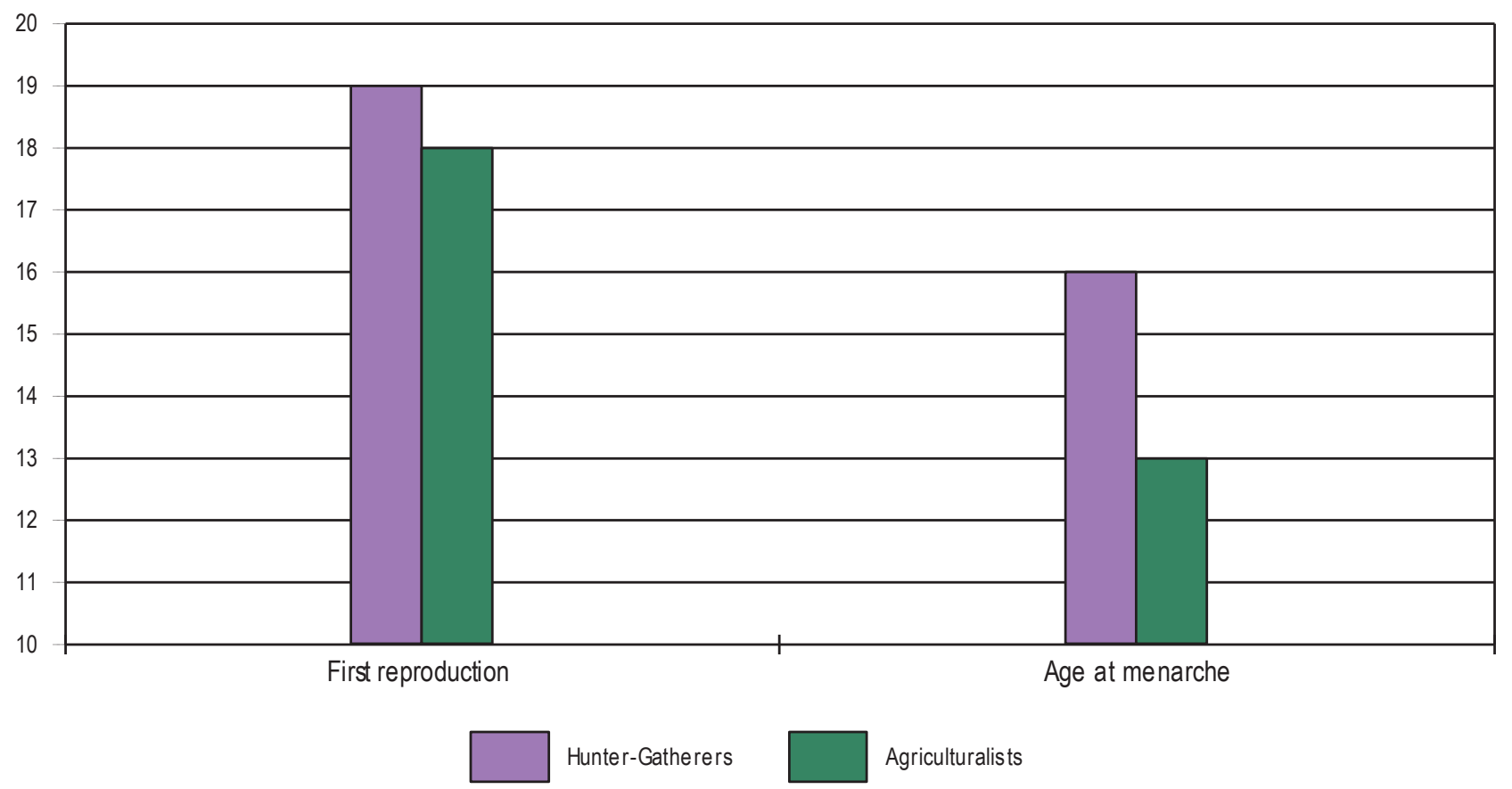

Figure 14. Comparison of selected life-history parameters (Trinkaus, Tompkins 1990). 


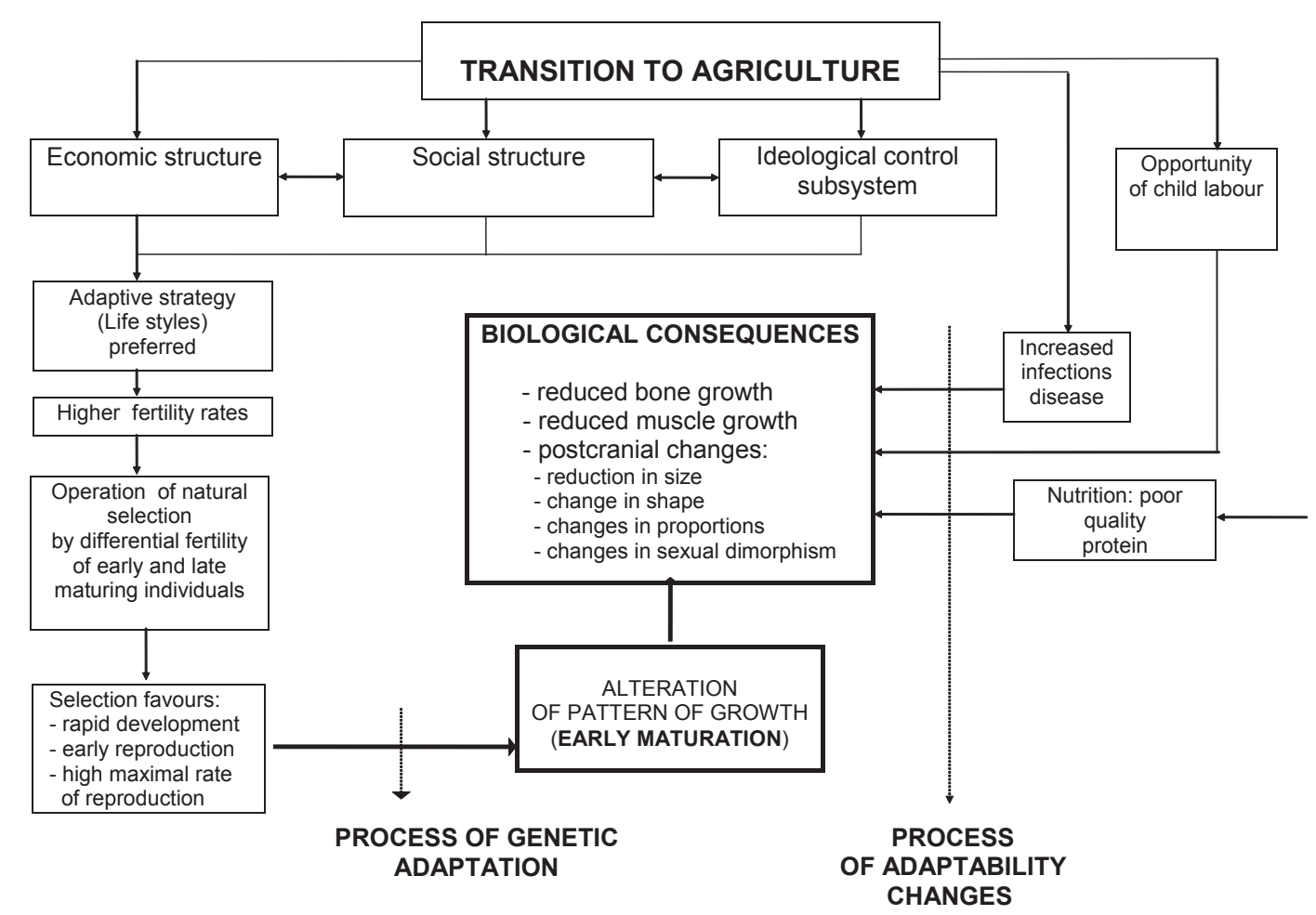

Figure 15. Model of Upper Paleolithic - Neolithic transition based on changes in adaptive strategies from hunter/gatherers to agriculture (Piontek 1999).

maturation and reproduction. Such a process, occurring in early agricultural communities, resulted in changes in the gene pools of these populations and had a strongly adaptive character, promoting genetic adaptation to new socio-economic conditions. In order to demonstrate that the changes identified above in body size and proportions were of an adaptive nature (a higher reproduction of earlier maturing individuals) we searched the relevant literature for data indicating a relationship between maturational pace and the shaping of body size and proportions. We were seeking to identify whether earlier maturating (and thus earlier reproducing) girls, differ with regard to body shape and size from those maturing later.

\section{The Palaeolithic-Neolithic transition - an analysis of microevolutionary trends}

We have found significant differences in the body build, body shape and limb proportions of the two most different groups studied, the PGM Upper Palaeolithic and the LBPC Neolithic populations. Upper Palaeolithic humans were much taller and had more robust bones in comparison with the LBPC Neolithic population. They had longer lower limbs, a shorter trunk and extremely long forearm and crural segments. Neolithic populations had a short trunk and lower limbs and extremely short forearms and crura.

A more detailed analysis has shown that it is no longer possible to analyse Upper Palaeolithic Homo sapiens populations living before and after the glacial maximum as one evolutionary group because they are markedly different both in body size parameters and in the pattern of sexual dimorphism. There are also differences in the morphological parameters of individual regions of the upper and lower limb long bones and bone proportions. While the PGM Upper Palaeolithic population forms a distinct group in terms of all the examined parameters, the LUP Upper Palaeolithic populations are in various features fairly similar to the Mesolithic populations, however, there are also significant differences among them. Both the LUP and Mesolithic populations are smaller in comparison with the PGM ones while their females are relatively small and not particularly robust.

The degree of sexual dimorphism in the LUP Homo sapiens is lower compared with the PGM populations with its character being comparable to that of the Neolithic and modern human populations, i.e., males are larger and more robust, while females are smaller and more gracile.

We have found two types of body build and sexual dimorphism among the Neolithic populations. The first one, found in early pastoral populations, is fairly similar to that of Mesolithic populations. The second one, typical of the early agricultural Neolithic populations, is completely different from both Palaeolithic and Mesolithic populations and from the pastoral European Neolithic populations. Early agriculturalists, represented in our study by the Linear Band Pottery Culture populations and the Lengyel Culture populations, were small with extremely robust males and extremely small, relatively gracile females. Their tibiae were relatively short, which could be linked with a relatively poor living standard or with the frequent environmental stresses to 
which early agricultural central European populations were typically exposed (Krenz-Niedbała 2000).

The Upper Palaeolithic populations have more robust epiphyses and longer diaphyses. There are extremely significant differences in the biomechanical structure of the lower limbs between the Upper Palaeolithic and Neolithic humans. The Upper Palaeolithic structure was adapted to dynamic locomotion with the lower limb axes situated maximally laterally. The Neolithic population had a biomechanical structure adapted to a more static posture and limited locomotion, and stressing of the lower limbs, with the limb axes close to the axis of the body. In terms of the biomechanical structure of the long bones, the Mesolithic skeletal sample seems to be intermediate between the Upper Palaeolithic and Neolithic samples.

As in the case of the body size, there is a marked difference between the PGM and LUP populations in bone length, and to a lesser degree in the biomechanical structure of the bones. Again, certain similarities can be found among the LUP, Mesolithic and early pastoral populations' long bones.

However, there are also significant differences among the LUP Upper Palaeolithic and post-Palaeolithic populations. They are linked by a common morphology. The most important differences exist between the proximal femur and distal tibial morphology, which can be ascribed to the biomechanical differences between Palaeolithic and Neolithic populations summarised above (see also Vančata 1988; 1993; 1997; Piontek 1999a; 1999b; 2001; Piontek Vančata 2002; 2004). In this respect the Mesolithic morphology is quite similar to the Neolithic one with typical adaptations to the more static type of locomotion, which also corresponds to the reconstructed behaviours of Mesolithic European populations.

The basic patterns of sexual dimorphism differ significantly in these groups. PGM Upper Palaeolithic males were extremely tall and relatively slim, while females were relatively small and robust or even extremely robust. Males had particularly long lower limbs, while females had relatively shorter ones. The PGM Upper Palaeolithic females were much smaller but also much more robust compared with the males. This pattern of sexual dimorphism is extremely rare in recent human populations.

The pattern of sexual dimorphism is remarkably different among the PGM and LUP Upper Palaeolithic populations. The LUP males are much smaller and less robust in comparison with the PGM males, while the LUP females are smaller and significantly more gracile than PGM females. Additionally, the character of sexual dimorphism in bone proportions differs significantly among the PGM and LUP populations. And again, marked similarities can be found among the LUP, Mesolithic and CWC populations with the exception of biomechanical features (see: the Morphological evidence section) which are similar among the Mesolithic and CWC Neolithic populations. The LBPC Neolithic population has a specific pattern of sexual dimorphism, with hyper-robust small males and extremely small gracile females.

The LBPC Neolithic males were relatively small and robust, while females were extremely small and more gracile compared with males. Size dimorphism is somewhat smaller in the LBPC LC Neolithic populations in comparison with the PGM Upper Palaeolithic ones.

Thus, there have been two basic evolutionary trends in body size and body shape changes during the origin of Neolithic populations. Populations with pastoral/horticultural economies (e.g., CWC Neolithic groups) had a body size and shape particularly similar in many features to the Mesolithic and also to the LUP Upper Palaeolithic group. In this respect the early agricultural populations (e.g., LPBC or LC Neolithic groups) represent groups with a new morphological pattern, having an extremely different body size and shape from both Mesolithic and pastoral Neolithic groups.

\section{Discussion}

Different sample size is one important aspect of any such investigation. While the number of Upper Palaeolithic skeletons obtained from a single site is usually small and the skeletons usually incomplete, the availability of relatively large numbers of Neolithic individuals is not uncommon.

This is one of the reasons why we do not stress the significance of an individual population and its specific features in our study. Instead, we focus on Neolithic populations with similar adaptive strategies, such as early agriculturalists or pastoralists from the Central European region. For these reasons we do not take into account hypothesized migrations or the regional origins of a given culture, which is usually the case in detailed studies of Neolithic populations. In this sense, we also apply a "classical" palaeoanthropological and evolutionary anthropological approach to the analysis of Neolithic populations.

As regards the number of measurements, it is evident that it was impossible to take the entire set of potential measurements for all the skeletons examined, particularly for the Upper Palaeolithic material ( $c f$. also Holliday 1995). The set of measurements taken from the literature was more limited than that used in our metric description of long bones for the reconstruction of body size and body shape (Vančata 1988). Nevertheless, data from the literature were quite sufficient for computing proportions and body size parameters, which were usually estimated from three or more morphological traits.

There is also a problem regarding the sexing of fossil samples and the possibility of regional differences between the samples. Sexing skeletons is a general problem for biological anthropology, namely for palaeoanthropology and historical (archaeological) anthropology, where morphology, and consequently also the morphological patterns important for sexing, may be very different in their expression from those characteristic of contemporary populations. Fortunately, analyses of fossil human populations reveal that there is a greater degree of sexual dimorphism than that characteristic of recent human populations. This enabled us to use a combination of size sexual dimorphism and 
morphological sexual dimorphism, which is particularly effective in the case of the Upper Palaeolithic populations.

In the majority of cases we took sex determinations from the original publications or from Museum catalogues; subsequently verified (or changed if necessary) by multivariate methods. Moreover, we have analysed basic regional differences for the Upper Palaeolithic populations (Vančata 1997; 2000) which has demonstrated the correctness of our definition of the pattern of Upper Palaeolithic sexual dimorphism.

The third problem regards the accuracy and consistency of the reconstruction of body height and body mass. The issues surrounding their estimation in fossil human populations has been discussed many times (e.g., Bach 1965; Feldesmann et al. 1989; 1990; Feldesman, Fountain 1996; Formicolla 1983; 1993; Formicolla, Franceschi 1996; Formicolla, Giannecchini 1999; McHenry 1991; 1992; Ruff et al. 1997; Ruff, Walker 1993; Sjøvold 1990; Vančata 1996; 1997; 2000; 2003; 2005; Wolpoff 1983). The precision and reliability of reconstructing body height, and eventually the body mass of fossil hominids has been dealt with in a number of studies (see, e.g., Formicolla 1993; Formicolla, Giannecchini 1999; Ruff, Walker 1993; Vančata 1997; 2000).

In our opinion, however, the main issue is not the precision of a given method as such but rather the lack of comparability between the various methods proposed, this being the main problem for palaeoanthropological and evolutionary anthropological studies. Each method, in fact, is based on a different sample and on a different regression formula.

This situation results in complete confusion, both in the data published by various authors for the same population and - which is much worse - in comparing what are, in fact, non-comparable results in evolutionary studies. While palaeoanthropologists have moved towards using more precise methods of body height estimation, based on the MA or RMA regression methods (Feldesmann et al. 1989; 1990; Feldesman, Fountain 1996; Jacobs 1993; Sjøvold 1990), historical anthropologists continue to use formulae based on the least square methods (e.g., Formicolla 1983; 1993; Formicolla, Franceschi 1996) with a priori determination of the sex of a studied individual.

Anumber of investigators use methods employing formulae based on body height to estimate body mass (Jungers, Stern 1983; Ruff, Walker 1993; Wolpoff 1983), while others use standard methods based on morphological parameters such as femoral head or cross-sections (Jungers 1988; McHenry 1988; 1992). The results of such studies are often contradictory, because they use only partial information, preferring to obtain a high number of estimates rather than assure their comparability (Myszka et al. 2012).

While it is possible to determine height in fossil human populations in certain cases (see Formicolla 1993, Formicolla, Giannecchini 1999), and the most appropriate method can be assessed (although only for a given population), there is no such possibility with regard to body mass estimates.

This is the reason why we have employed our own approach to estimating both body height and body mass, which is perhaps less precise for particular individuals, but which enables us to obtain a reliable estimate of population variability, and carry out a consistent comparative analysis.

However, we must keep in mind that we cannot legitimately say that body height and body mass for a given population are precise values; rather they represents mid-points for the most reliable estimates for the population under study. Similarly, we must keep in mind that it is impossible to estimate particular values of, for example, subcutaneous body fat, so that estimated body mass is always an optimum value.

One of the most important features of this approach is that we estimate not only body height and body mass but also their relations, for example the skeletal body mass index. This is informative with regard to general body build for a given population, and thus is extremely important for understanding the nature of sexual dimorphism in the population. All the estimated parameters are never as precise as the original measurements but are integrative parameters, summarizing the characters of various parts of the postcranium that are directly comparable for any sample, because we are using the same approach and the same method for each individual studied. In this way, we can easily analyse important ecological features such as body size, body shape and limb proportions in relation to any social and/or environmental factors.

The fourth issue regards the dating of the fossil finds, and relevant ecological and archaeological evidence for the model. Estimated dates for the fossil samples, and other populations, have been taken from the literature (see e.g., Holliday 1995; 1997; Jankowska et al. 1999; Ruff et al. 1997; Vančata 1997), which we assume to be relatively accurate. However, this study is an evolutionary anthropological one and dating issues are beyond its scope. In this sense, the archaeological and palaeoecological evidence for the model is much more important than the dating itself.

\section{Conclusions}

We have found significant differences between the preglacial Upper Palaeolithic populations and early agricultural Neolithic populations in: 1. body size, body shape and limb proportions; 2. basic biomechanical limb parameters and limb robusticity; 3 . sexual dimorphism, in both body size and shape, and in proportions and biomechanical structure of limbs.

The process of body reshaping from body shape of PGM Upper Palaeolithic populations to that typical for Neolithic early agriculturalists was not rapid, but proceeded in two steps - the LUP and Mesolithic phases - which were probably closely related to changes in the ecology of individual populations influenced by factors such as the size of game, availability of food resources, structure of the territory, social structure and reproduction rate. We have also found that the Mesolithic, being a typically European rather than universal phenomenon, can be substituted in certain regions with the early pastoral phase, as a similar type of ecology can be assumed on the basis of the above-mentioned criteria. 
The differences observed between Upper Palaeolithic and Neolithic populations are a result of multiple biological and cultural factors which combined the effect of a new adaptive strategy and subsistence pattern. This strategy promoted a high fertility and mortality rates in agricultural populations, and we can assume that natural selection most probably operated on early agricultural Neolithic populations by differential fertility of slower and faster developing individuals. In the transition to agriculture we observed differences of the same type as the differences between the slower and faster developing individuals in contemporary populations. This trend in body form changes is a major evolutionary event, since this shift of the ontogenetic pathway must have had a strictly genetic basis.

\section{Acknowledgements}

We would like to thank Jiří Svoboda (Archaeological Institute, Academy of Sciences, Brno and Institute of Anthropology, Faculty of Science, Masaryk University, Brno) and Míla Dobisíková and Vitězslav Kuželka (National Museum, Prague) for enabling us to study the fossil material. We are also greatly indebted to Erik Trinkaus and Trent Holliday for sending us certain unpublished data on Palaeolithic and Mesolithic populations. This study was partially supported by Grant projects GA AV ČR No. 405/05/2552, No. 206/93/1029, No. 206/96/0166 and Grant project GA UK 218/2005/B-BIO/.

\section{References}

AMMERMANN A. J., CAVALLI-SFORZA L. 1984: The Neolithic Transition and the Genetics of Populations in Europe. Princeton University Press, Princeton.

BACH, A. 1965: Zur Berechnung der Körperhöhe aus den langen Gliedmassenknochen weiblicher Skelette, Anthropological Anzeiger 29: $12-21$.

BACH, A. 1978. Neolitische Populationen in Mittelelbe-Saale-Gebiet. Weimar Monographien zur Ur- and Frühgeschichte, Weimar.

BACH, H., BACH, A. 1981: Robustizitätverhältnisse und Körperhöhenentwicklung bei Neolithischen and Frühbronzezietlichen Bevölkerungen des Mittelelbe-Saale-Gebietes, Beiträge zur Ur- und Frühgeschichte I, 16, 185-195.

BARBUJANI, G., PILASTRO, A., de DOMENICO, S., RENFREW, C. 1994: Genetic Variation in North Africa and Eurasia: Neolithic Demic Diffusion vs. Paleolithic Colonisation, American Journal of Physical Anthropology 95, 137-154.

BENTLEY, G. R., JASIEŃSKA, G., GOLDBERG, T. 1993: Is the fertility of agriculturists higher than that of non-agriculturists? Current Anthropology 34, 785-788.

BOGUCKI, P. 1982: Early Neolithic Subsistence and Settlement in the Polish Lowlands. British Archaeological Reports (International Series 150), Oxford.

BOGUCKI, P. 1988: Forest Farmers and Stockherders: Early Agriculture and its Consequences in North-Central Europe. Cambridge University Press, Cambridge.

CZERNIAK L., 1980: Rozwój społeczeństw kultury późnej ceramiki wstegowej na Kujawach. Wydawnictwa Naukowe UAM, Poznań.

CZERNIAK L., 1994: Wczesny i środkowy okres neolitu na Kujawach. 5400-3650 p. n. e. Wydawnictwo Instytutu Archeologii PAN, Poznań.

ÉRY, K. 1998: Length of limb bones and stature in ancient populations in the Carpathian Basin, Humanbiologia Budapestinensis 26: 1-86.
FELDESMAN, M. R., FOUNTAIN, R. L. 1996: "Race" specificity and the femur stature ratio, American Journal of Physical Anthropology 100, 207-224.

FELDESMAN, M. R., KLECKNER, J. G., LUNDY, J. K. 1990: The femur/ stature ratio estimates of stature in mid- and late-Pleistocene fossil hominids, American Journal of Physical Anthropology 83, 359-372.

FELDESMAN, M. R., LUNDY, J. K., KLECKNER, J. G. 1989: The femur/ stature ratio estimates of stature in mid- and late-Pleistocene fossil hominids, American Journal of Physical Anthropology 78, 219-220.

FORMICOLLA, V. 1983: Stature in Italian prehistoric samples with particular references to methodological problems, Homo 34, 33-47.

FORMICOLLA, V. 1988: The triplex burial of Barma Grande, Homo 39, $130-143$.

FORMICOLLA, V. 1993: Stature reconstruction from long bones in ancient population samples: An approach to the problem of its reliability, American Journal of Physical Anthropology 90, 351 - 358.

FORMICOLA, V. 2003: More is not always better: Trotter and Gleser's equations and stature estimates of Upper Paleolithic European samples, Journal of Human Evolution 45, 239-243.

FORMICOLLA, V., FRANCESCHI, M. 1996: Regression equations for estimating stature from long bones Early Holocene European samples, American Journal of Physical Anthropology 100, 83-88.

FORMICOLLA, V., GIANNECCHINI, M. 1999: Evolutionary trends of stature in Upper Paleolithic and Mesolithic Europe, Journal of Human Evolution 36, 319-333.

FRAYER, D. W. 1980: Sexual Dimorphism and Cultural Evolution in the Late Pleistocene and Holocene of Europe, Journal of Human Evolution 9, 399-415.

FRAYER, D. W. 1981: Body Size, Weapon Use and Natural Selection in the Upper Paleolithic and Mesolithic Europe, American Anthropologist 83, 57-73.

FRAYER, D. W. 1984: Biological and Cultural Change in the European Late Pleistocene and Early Holocene. In: Smith, F. H., Spencer, F. (Eds.): The Origins of Modern Humans. A World Survey of Fossil Evidence. Alan R. Liss, Inc., New York, 211-250.

FRAYER D. W., WOLPOFF, M. H. 1985: Sexual dimorphism, Annual Review of Anthropology 14, 429-473.

GAMBLE, C. 1995: Timewalkers. The Prehistory of Global Colonization. Penguin Books, London (first published by Allan Sutton Publishing 1993).

GALETA, P., BRŮŽEK, J. 2009 : Demographic model of the Neolithic transition in Central Europe, Documenta Praehistorica 34, 139-150.

GRYGIEL, R., BOGUCKI, P. 1997: Early Farmers in North-Central Europe: 1989-1994. Excavations at Osłonki, Poland, Journal of Field Archaeology 24, 161-178.

HAAK, W., FORSTER, P., BRAMANTI, B., MATSUMURA, S., BRANDT, G., TANZER, M., VILLEMS, R., RENFREW, C., GRONENBORN, D., ALT, K. W. et al. 2005: Ancient DNA from the First European Farmers in 7500-Year-Old Neolithic Sites, Science 310 (5750), 1016-1018.

HASSAN, F. A. 1973: On mechanisms of population growth during the Neolithic, Current Anthropology 14, 535-540.

HASSAN, F. A. 1978: Demographic archaeology. In: Schiffer, M. (Ed.): Advances in archaeological method and theory 1. Academic Press, New York, 49-103.

HASSAN, F. A. 1979: Demography and archaeology, Annual Review of Anthropology 8, 137-160.

HASSAN F. A. 1981: Demographic Archaeology. Academic Press, New York.

HERSHKOVITZ, I., SPEIRS, M. S., FRAYER, D., NADEL, D., WISHBARATZ, S., ARENSBURG, B. 1995: Igaki II H2: A 19,000-Year-Old skeleton from a water-logged site at the sea of Galilee, Israel, American Journal of Physical Anthropology 96, 215-234.

HOLLIDAY, T. W. 1995: Body Size and Proportions in the Late Pleistocene Western Old World and the Origins of Modern Humans. MS. Ph.D. thesis. Deposited: University of New Mexico, Albuquerque.

HOLLIDAY, T. W. 1997: Body Proportions in Late Pleistocene Europe and modern human origins, Journal of Human Evolution 32, 423-447.

JANKOWSKA, D., KRENZ-NIEDBAŁA, M., PIONTEK, J., WIERZBICKI, J. 1999: Biological and cultural Consequences of the Transition to Agriculture in Central Europe. Monografie Instytutu Antropologii UAM 4, Poznań. 
JACOBS, K. J. 1985a: Evolution in the postcranial skeleton of late Glacial and Postglacial European hominids, Zeitschrift Morphologie und Anthropologie 75, 307-326.

JACOBS, K. J. 1985b: Climate and the Hominid Postcranial Skeleton in Wurm and Early Holocene Europe, Current Anthropology 26, 512-514.

JACOBS, K. J. 1992: Estimating femur and tibia length from fragmentary bones: an evaluation of Steele's (1970) method using a prehistoric European sample, American Journal of Physical Anthropology 89: 333 345

JACOBS, K. J. 1993: Human postcranial variation in the Ukrainian Mesolithic-Neolithic transition, Current Anthropology 34: 311-324.

JUNGERS, W. L. 1988: New estimates of body size in australopithecines. In: Grine, F. E. (Ed.): Evolutionary History of the "Robust" Australopithecines. Aldine de Gruyter, New York, 115-125.

JUNGERS, W. L., STERN, J. T. 1983: Body proportions, skeletal allometry and locomotion in the Hadar hominids: a reply to Wolpoff, Journal of Human Evolution 12, 673-684.

KRENZ-NIEDBAŁA, M. 2000: Biological and cultural consequences of the transition to agriculture in human populations on Polish territories (in Polish). Monografie Instytutu Antropologii UAM, Poznań.

KRENZ-NIEDBAŁA, M. 2001: Biological and cultural consequences of the transition to agriculture in human populations on Polish territories, Variability and Evolution 9: 89-99.

KRUK, J., MILISAUSKAS, S. 1999: The Rise and Fall of Neolithic Societies. Institute of Archeology and Ethnology PAS, Kraków.

KRZAK, Z. 1976: The Złota Culture. Ossolineum, Wrocław-WarszawaKraków-Gdańsk.

KRZAK, Z. 1989. Złota Culture. Złota near Sandomierz, Tarnobrzeg province. Sites "Grodzisko I" and "Nad Wawrem", Cemeteries, Przegląd Archeologiczny 36, 255-269.

LARSEN, C. S. 1987: Bioarcheological interpretations of subsistence economy and behavior from human skeletal remains. In: Schiffer, M B. (Ed.): Advances in Archaeological Method and Theory 10. Academic Press, San Diego, 339-445.

LARSEN, C. S. 1990. The Archaeology of Mission Santa Catalina De Guale: 2. Biocultural Interpretations of a Population in Transition. Anthropological Papers of the American Museum of Natural History, Number 68. The American Museum of Natural History, New York

LARSEN, C. S. 1995: Biological changes in human populations with agriculture, Annual Review of Anthropology 24, 185-213.

MACHNIK, J. 1979: Krąg kulturowy ceramiki sznurowej. In: Hensel, W. Wiślański, T. (Eds.): Prahistoria ziem polskich, vol. 2, Neolit. Ossolineum, Wrocław, 337-411.

MATIEGKA, J. 1938: Homo předmostensis: Fosilní člověk z Předmostí na Moravě. II. Ostatní části kostrové. Česká akademie věd a umění, Praha.

McHENRY, H. M. 1988: New estimates of body weight in early hominids and their significance to encephalization and megadontia in ,robust" australopithecines. In: Grine, F. E. (Ed.): Evolutionary History of the "Robust" Australopithecines. Aldine de Gruyter, New York, 133-148.

McHENRY, H. M. 1991: Sexual dimorphism in Australopithecus afarensis, Journal of Human Evolution 20, 21-32.

McHENRY, H. M. 1992: Body size and proportions in early hominids, American Journal of Physical Anthropology 87, 407-431.

MILISAUSKAS, S., KRUK, J. 1989: Neolithic economy in Central Europe, Journal of World Prehistory 3, 403-446.

MYSZKA, A., PIONTEK, J., VANČATA, V. 2012: Body mass reconstruction on the basis of selected skeletal traits, Anthropologischer Anzeiger 69, 305-315.

OLIVIER, G. 1976. The stature of australopithecines, Journal of Human Evolution 5, 529-534.

PINHASI, R. 2004: A new model for the spread of the first farmers in Europe, Documenta Praehistorica 30, 1-76.

PINHASI, R, von CRAMON-TAUBADEL, N. 2009: Craniometric Data Supports Demic Diffusion Model for the Spread of Agriculture into Europe, PLoS ONE 4(8):e6747.

PINHASI, R., von CRAMON-TAUBADEL, N., in press: Cranial variation and the transition to agriculture in Europe, Human Biology 84/1, article 3.

PIONTEK J. 1989: Biological consequences of the "Neolithic revolution": The case of the Middle European populations. In: Hershkovitz I. (Ed.) People and Culture in Change. BAR International Series 508, Tel Aviv, 177-195.
PIONTEK, J. 1999a: Patterns of adaptive strategy in the Upper Paleolithic and post-Paleolithic populations: Evidence from Central Europe In: Ullrich H. (Ed.): Human Evolution and Environment. Humboldt Universität, Berlin, 187-204.

PIONTEK, J. 1999b: Body Size and Proportions in the Upper PalaeolithicNeolithic Transition: Evidence from Central Europe. In: Biological and Cultural Consequences of the Transition to Agriculture in Central Europe. Monografie Instytutu Antropologii UAM 4, Poznań, 61-84.

PIONTEK, J. 2001: Culture as a Human Adaptive System: Human Ecology and Culture. In: Tobias, F. et al. (Eds.): Humanity from African Naissance to Coming Millennia. Firenze University Press, Firenze, 47-54.

PIONTEK, J., VANČATA, V. 2002: Transition to Agriculture in Europe: Evolutionary Trends in Body Size and Body Shape. In: Biennial Books of EAA 2. 61-92.

PIONTEK, J., VANČATA, V. 2004: Two models of the adaptive strategy of the Neolithic populations in Central Europe (early pastoral and agricultural) and their biological consequences. In: Kośko A., Szmyt M. (Eds.): Nomadyzm i pastoralizm $w$ międzyrzeczu Wisty i Dniepru (neolit, eneolit, epoka brąu). Wydawnictwo Poznańskie, Poznań, 255-268.

RUFF, C. B. 1987: Sexual dimorphism in human lower limb bone structure: Relationship to subsistence strategy and sexual division of labour, Journal of Human Evolution 16, 391-416.

RUFF, C. B., LARSEN, C. S., HAYES, W. C. 1984: Structural changes in the femur with the transition to agriculture on the Georgia cost, American Journal of Physical Anthropology 64, 125-136.

RUFF, C. B., TRINKAUS, E., HOLLIDAY, T. F. 1997: Body mass and encephalization in Pleistocene Homo, Nature 387, 173-175.

RUFF, C. B., WALKER, A. 1993: Body size and body shape. In: Walker, A., Leakey, R. E. (Eds.): The Nariokotome Homo erectus Skeleton. Harvard University Press, Cambridge, 234-265.

SJØVOLD, T. 1990. Estimation of stature from long bones utilising the line of organic correlation, Human Evolution 5, 431-447.

TABACZYŃSKI, S. 1970: Neolit środkowoeuropejski. Podstawy gospodarcze. Wrocław - Warszawa - Kraków.

TANNER, J. M. 1962: Growth and Adolescence. 2nd ed., Blackwell Scientific Publications, Oxford.

TRINKAUS, E., TOMPKINS, R. L. 1990: The Neanderthal life cycle: The possibility, probability, and perceptibility of contrasts with recent humans. In: De Rousseau, C. J. (Ed.): Primate life history and evolution. Wiley-Liss, New York, 153-180.

TRINKAUS, E., JELÍNEK, J. 1997: Human remains from the Moravian Gravettian: The Dolní Věstonice 3 postcrania, Journal of Human Evolution 33, 33 - 82

VANČATA, V. 1988: Ecological aspects of skeletal sexual dimorphism in microevolution of Homo sapiens, Anthropologie 26, 83-92.

VANČATA, V. 1991: Evolution of higher primate femur and tibia: Adaptive morphological patterns and phylogenetic diversity, Human Evolution 6, $1-47$

VANČATA, V. 1993: Evolution of hominid femur and tibia: A morphometric approach to the evolutionary research in anthropology, Human Evolution 8 (2), 65-79.

VANČATA, V. 1994: Základní metrické znaky a proporce dlouhých kostí dolní končetiny nálezu čtyř jedinců (DV-XIII, DV-IV, DV-XV, DV-XVI) ze svrchně paleolitického naleziště Dolní Věstonice, Časopis Národniho Musea - řada prírodovédná 159, 144-155.

VANČATA, V. 1996: Major Patterns of Early Hominid Evolution: Body size, proportions, encephalisation and sexual dimorphism, Anthropologie 34 (1-3), 313-328.

VANČATA, V. 1997: Body Size and Shape as an Indicator of Important evolutionary and Evolutionary Changes in Hominoid Phylogeny (in Czech). MS. Habilitation thesis. Deposited: Charles University, Prague.

VANČATA, V. 2000: Reconstruction of body height, body mass and body shape in fossil and historical human populations. In: Charzewski, J., Piontek, J. (Eds.): Nowe techniky i technologie badan materialow kostnych. Akademia Wychowania Fyzicznego Jósefa Pilsudkiego, Warszawa, 11-34.

VANČATA, V. 2003: Sexual Dimorphism in Body Size and Shape in Pavlovian Upper Paleolithic Group: A population approach, Anthropologie $41 / 3,213-240$ 
VANČATA, V. 2005: A preliminary analysis of long bone measurements of Homo floresiensis: Bone robusticity, body size, proportions and encephalisation, Antropologie 42 (2-3), 273-282.

WOLPOFF, M. H. 1983: Lucy's little legs, Journal of Human Evolution $12,443-453$.

ZVELEBIL, M. 1995: At interface of archaeology, linguistic and genetics: Indo-European dispersals and the agricultural transition in Europe, Journal of European Archaeology 3/1, 33-70.
ZVELEBIL, M., LILLIE, M. 2000: The transition to agriculture in Eastern Europe. In: Price, T. D. (Ed.): Europe's first farmers. Cambridge University Press, New York, 57-92.

ZVELEBIL, M. 2001: The agricultural transition and the origins of Neolithic society in Europe, Documenta Praehistorica 28, 1-26. 